\title{
A methodology to surface aspects of organisational culture to facilitate lean implementation within SMEs
}

\section{Abdullah Abdulaziz Alkhoraif* and Patrick McLaughlin}

Manufacturing Department,

School of Aerospace, Transport and Manufacturing,

Cranfield University, Cranfield, Bedfordshire, MK43 0AL, UK

Email: a.a.alkhoraif@cranfield.ac.uk

Email: p.mclaughlin@cranfield.ac.uk

*Corresponding author

\begin{abstract}
The purpose of this paper is to provide an instructional guidance on how to surface aspects of organisational culture (OC) that effect lean implementation within small and medium sized manufacturing organisation. This paper describes how grounded theory and action research can be used inside each other. The paper suggests to not only using a translation method to validate the result but to use also inter-rate reliability to increase the validity and reduce the subjectivity. The paper also demonstrates how different technique can help management research by including in a time effective way.
\end{abstract}

Keywords: lean implementation; LI; organisational culture; OC; grounded theory; action research; small and medium-sized enterprises; SMEs.

Reference to this paper should be made as follows: Alkhoraif, A.A. and McLaughlin, P. (xxxx) 'A methodology to surface aspects of organisational culture to facilitate lean implementation within SMEs', Int. J. Operational Research, Vol. X, No. Y, pp.xxx-xxx.

Biographical notes: Abdullah Abdulaziz Alkhoraif is a $\mathrm{PhD}$ researcher assistant at the School of Aerospace Transportation and Manufacturing, Cranfield University. He holds degree in BEng Engineering and Business and MSc Engineering Project Management form the Bournemouth University. Recently, he published two books in The Process of Quality Material Selection and Contractual and Sub-contractual risks: Project Management Perspective. He was involved in oil industry for 10 years.

Patrick McLaughlin is a Course Director: Operations Excellence MSc, School of Aerospace Transportation and Manufacturing, Cranfield University. He is a Chartered Engineer and Eur. Ing. He is a fellow of both the Institution of Mechanical Engineers and the Institution of Engineering and Technology, as well as a fellow of the Higher Education Academy. He has an MSc in Industrial Engineering and Production Management and a Doctorate in Business Administration (DBA), both from the Cranfield. He has worked at director level in manufacturing operations for over 20 years, and has been responsible for several plant-wide lean manufacturing implementations. He has experience of implementing and managing change programmes to improve manufacturing performance in automotive, capital goods, industrial equipment and consumer durables. This experience includes responsibility for integrating the design and development of new products into a lean operations environment and developing a continuous improvement culture to facilitate performance gains in lean implementations.

Copyright (C) 2021 Inderscience Enterprises Ltd. 
This paper is a revised and expanded version of a paper entitled 'A methodology to surface aspects of organizational culture to facilitate lean implementation within SMEs' presented at 2nd International Conference on Business and Social Sciences, Cambridge University, UK, 11-12 November 2017.

\section{Introduction}

Developing a framework addressing the need for an OC to better facilitate a lean culture and propel its success among small and medium-sized enterprises (SMEs) requires a methodology that supports the research and analysis of OCs regarding lean implementation (LI) (Alkhoraif and McLaughlin, 2018; Kumar et al., 2018; Wood et al., 2018). Therefore, for the purposes of this research it is crucial to incorporate suitable research methods that address OCs and its issues. The way in which the methodology was implemented is discussed and analysed in the following sections, evaluating the pros and cons of methodological options such as case study, phenomenology, grounded theory, laddering, action research, cognitive mapping and ethnography.

The aim of the research is to develop a methodology to surface aspects of organisational culture (OC) that facilitate LI within SMEs manufacturing sector. There is a need of a methodology to improve LI within SMEs (Alkhoraif and Mclaughlin, n.d., 2017, 2018; Ravikumar et al., 2016; Wood et al., 2018). In addition, Ravikumar et al. (2016) state that in terms of OC, a clear methodology is required to surface aspects of culture. The research was based on grounded theory methodology and a participative action research approach to uncover issues that clearly illustrated both the presence and intensity of aspects of organisation culture that enabled and inhibited LI within an inductive approach. Due to the need to explore OC it is beneficial to utilise qualitative research (Graham and Thomas, 2008). An inductive approach enables the researcher to become fully engaged within the research environment, thus improving the understanding of the culture being studied, facilitating more of an insider's view of the culture (Walker and Myrick, 2006).

Furthermore, it is important to note that most methodologies require extensive literature reviews to inform the research and identify the research question, as most research methodology is conducted with a deductive approach, (Dick, 2006). In contrast, grounded theory being inductive ends with a theory as opposed to beginning with a hypothesis and instead is used as a method for reviewing literature (Trochim and Donnelly, 2001). Hence, why research hypotheses are made redundant in grounded theory is that the literature is generally used as a comparator (Dick, 2006).

A combination of issues and phenomenological approaches proposed by Sackmann (2006) was utilised due to its suitability to analysing OC. In addition to this, the grounded theory method of Strauss and Corbin (1994) was adopted. Action research tends to be used for prompting conscious change within a somewhat controlled environment (Collis and Hussey, 2013). In this approach the participants and the researcher collaborate to find a solution to a problem (Coghlan and Brannick, 2014). 


\subsection{OC and research issues}

OC is a social science that has been discussed and brought up in many business disciplines. Yet, there is a lack of empirical research that adequately uncovers the integral nature of $\mathrm{OC}$ and its impact on organisations and their functioning (Pearse and Kanyangale, 2009). This is partly the result of the existence of abstract concepts in OC making it more complicated to research, (Sackmann, 1991). However, the following will attempt at proposing an appropriate research methodology suitable for researching OC.

In part, the problem exists in adequately defining culture and that in a number of cases, many of the fundamental aspects of culture which include beliefs, customs, value systems, behavioural norms and tangible or visible artefacts can be easily missed in research methods or over-simplified (Pearse and Kanyangale, 2009). Schein (1984) suggests that a number of methods utilised by those analysing OC take the approach of merely asking the correct questions. The other alternative might be to adopt a structured questionnaire, although the limitation with this is that it needs a strong understanding of the cultural context in which the OC is set (Sackman, 1991). This is usually not the case when approaching this kind of research (Bryant, 2009). Therefore, the issue of very thinly distributed empirical knowledge and research on OC and its context leads towards the use of a more inductive research approach (Golden-Biddle and Locke, 2007). This is because an inductive approach is better able to facilitate the establishment of a theory of culture within an organisational context, although, it can be difficult making comparisons between organisations with this approach (Sackmann, 1991).

Figure 1 The cultural iceberg model

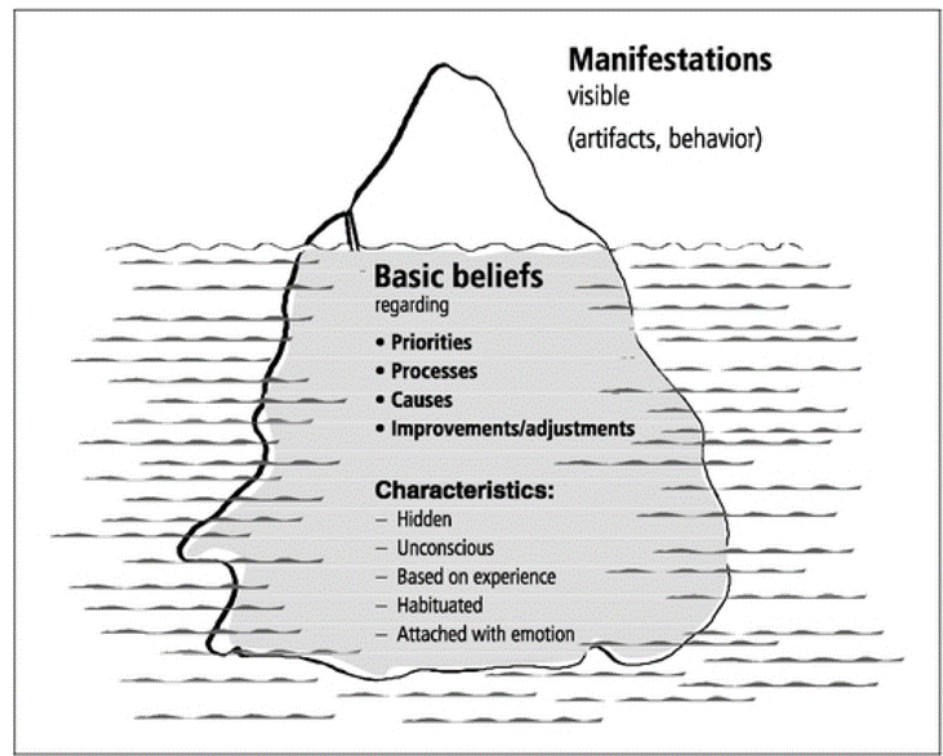

Source: Adopted from Sackmann (2006)

Among the many different definitions of culture, it can be defined as "... a set of assumptions commonly held by a group of people. The set is distinctive to the group. The 
assumptions serve as guides to acceptable perceptions, thought, feeling and behaviour, are tacit among members, are learned and are passed on to each new member of the group" [Phillips, (1994), p.6]. With this definition in mind, it requires revealing assumptions or beliefs, which serve as the premise behind how people perceive things, think, feel and behave (Golden-Biddle and Locke, 2007). Artefacts and behaviours tend to be more surface level and not necessarily reflective of the underlying cognitive components (Birkinshaw et al., 2011). One way to consider culture is like an iceberg (see Figure 1), with artefacts, behaviours and espoused assumptions at the tip, and below the surface lies the tacit, commonly held, habitually used an emotionally anchored component which are structure of cultural realities (Birkinshaw et al., 2011). Gaining an understanding of these is critical in order to work out the visible aspects but to draw these out requires special techniques (Allard and Anderson, 2005). The following section will highlight the methods best suitable to help reveal these deeper, structural components of a culture.

\section{Research paradigm}

It is essential to select an appropriate research paradigm that reflects the nature and characteristics of the area of study (Strauss, 1987). According to Strauss (1993), "This is a universe where nothing is strictly determined. Its phenomena should be partly determinable via naturalistic analysis, including the phenomenon of men [and women] participating in the construction of the structures which shape their lives" [Strauss, (1993), p.19]. Thus, it would make sense to consider the type of methodological philosophy that encompasses the complexity and ambiguity of inbuilt events and behaviour as described in Strauss's quote above. It suggests that what essentially is considered 'done procedure' and works today is quite likely to be problematic in the future (Guba and Lincoln, 1989). This necessitates a theory that helps to answer the questions of today but takes into account that these may likely turn back into questions in the future (Guba and Lincoln, 1989). Table 1 provides descriptions of paradigms which tend to compete for selection in guiding an inquiry in qualitative research.

Table 1 Methodological philosophical options

\begin{tabular}{|c|c|c|c|}
\hline & Positivism & Post positivism & Constructivism \\
\hline Ontology & $\begin{array}{l}\text { 'Naive realism - 'real' } \\
\text { reality but apprehendable' }\end{array}$ & $\begin{array}{l}\text { 'Critical realism - 'real' } \\
\text { reality but only imperfectly } \\
\text { and probabilistically } \\
\text { apprehendable' }\end{array}$ & $\begin{array}{l}\text { 'Relativism, local } \\
\text { and specific } \\
\text { constructed } \\
\text { realities' }\end{array}$ \\
\hline Epistemology & $\begin{array}{l}\text { 'Dualist/objectivist findings } \\
\text { are true' }\end{array}$ & $\begin{array}{l}\text { 'Modified dualist; } \\
\text { objectivist critical } \\
\text { traditional/community } \\
\text { findings probably true' }\end{array}$ & 'Interpretivist' \\
\hline Methodology & $\begin{array}{l}\text { 'Experimental/manipulative } \\
\text { verification of hypotheses; } \\
\text { chiefly quantitative } \\
\text { methods' }\end{array}$ & $\begin{array}{c}\text { 'Modified } \\
\text { experimental/manipulative } \\
\text { critical multiples; } \\
\text { falsification of hypotheses } \\
\text { may include qualitative } \\
\text { methods' }\end{array}$ & $\begin{array}{l}\text { 'Hermeneutical/ } \\
\text { dialectical' }\end{array}$ \\
\hline
\end{tabular}

Source: Guba and Lincoln (1989) 
Ontology - naïve realism (Table 1, column 1) is propelled by unchanging natural laws. Knowledge of the way things are is comprised over time and can sometimes show up in cause and effect laws (Hesse, 1980). Epistemology - dualist and objectivist operate as independent units, and the researcher is able to study the object without influencing it or being influenced by it (Guba and Lincoln, 1994). Methodology - experimental and manipulative involves stating questions or hypotheses and go under empirical testing (Guba and Lincoln, 1994).

Ontology - critical realism (column 2) is considered critical because its claims about reality is heavily scrutinised to facilitate the reality as closely as possible (Guba and Lincoln, 1994). Methodology - modified experimental emphasises triangulation as a way of falsifying hypotheses (Guba and Lincoln, 1994). It aims to address some weaknesses such as those discussed above by facilitating an insider view to help identify the context and purpose surrounding the actions. These are mainly achieved through a greater use of qualitative techniques (Hesse, 1980).

Figure 2 Philosophical methodological process for the current research (see online version for colours)

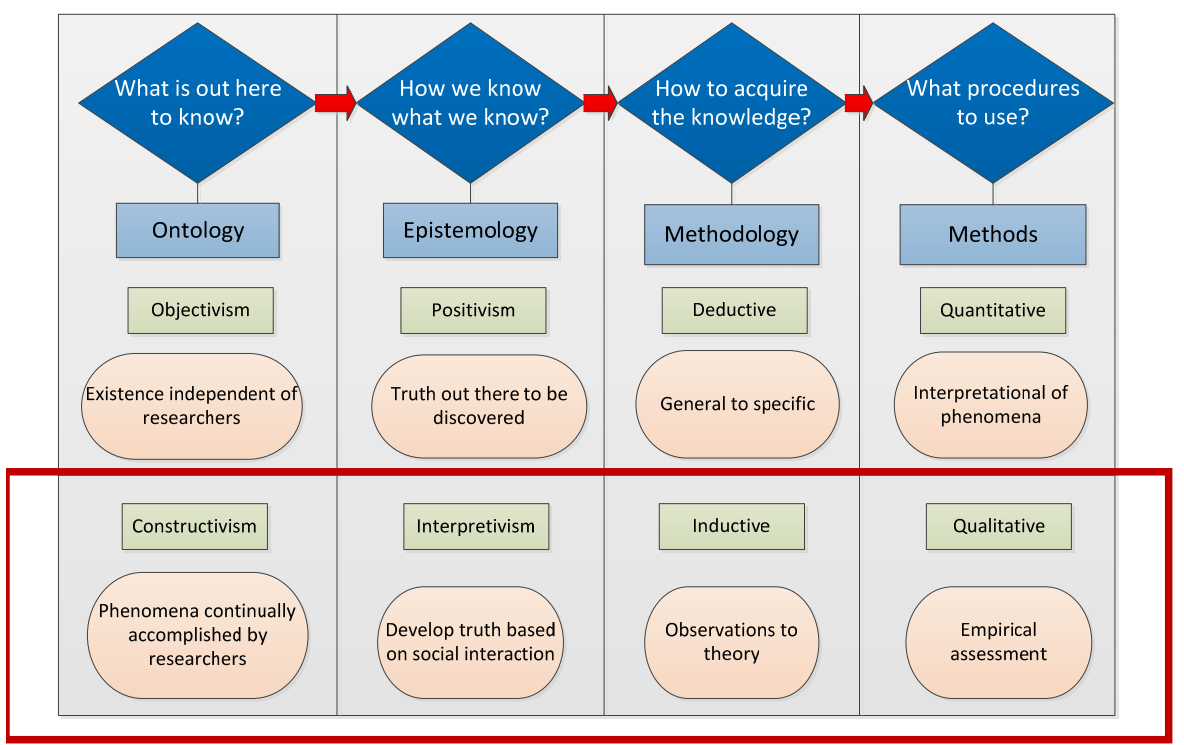

For this study, the constructivist approach has been selected. Ontology - constructivist (column 3) considers non-physical, mental constructions that are socially and experimentally-based, which might be local and specific in nature. Constructions can be altered because they are linked to realities (Guba and Lincoln, 1994). Epistemology interpretative considers the researcher and the object are interactively linked, which means the results are created as the research proceeds, (von Wright, 2004). In this case, the distinction between ontology and epistemology is eliminated. Methodology hermeneutical and dialectical suggests that individual's construction can only be drawn out by interaction between the researcher and the object (Guba and Lincoln, 1994). The 
aim is to identify a consensus construction which is more informed than the earlier construction. The red square in Figure 2 indicates the selection of the research approach.

\subsubsection{Ontology}

Ontology refers to the 'nature of reality and its characteristics' [Creswell, (2013), p.20]. It poses the questions relating to the form and nature of reality and what can be discovered about it (Guba and Lincoln, 1994). Researchers tend to show their ontological options along a continuum with the polar opposites being positivism and constructionism and the middle being realism (Blaikie, 2009). Where a positivist view was taken it considered that an "external reality existed, which could be discovered and totally understood" [Howell, (2012), p.4]. Thus, is it also referred to as 'naive realism'.

Under a post-positivism view, reality is believed to be understood imperfectly and thus emphasises a more critical evaluation of the existing reality (Howell, 2012). Thus, the notion is that reality is moulded by 'social, political, cultural, economic and ethnic and gender values', which are formed over time (Guba and Lincoln, 1994). Easterby-Smith et al. (2012) suggests the main characteristic of positivism is where the observer is independent from what is being studied and forms the choice of what to study. Thus, the choices are made by an objective criterion as opposed to human beliefs and decisions. The positivist position aims to find casual explanations and by testing hypotheses. Due to this in order for concepts to be measured they need to be simplified.

There are two main strands of realism in social sciences; one is transcendental and critical realism and the other is constructivist realism. According to Howell $(2012$, p.51) critical realism takes into account "a distinction between the knowledge of human being, which can change and knowledge that is of things... which is discovered." Realism sits between the pure positivist and constructionist views of reality (Marcos-Cuevas, 2006). According to realists, social sciences should adopt the anti-positivist position, suggesting there are distinct differences between natural and social phenomena (Marcos-Cuevas, 2006). Realists tend to accept an interpretative view that society is produced and reproduced by the members within it, thus 'are both a condition and an outcome their reality' [Blaikie, (2009), p.59]. Realism is more concerned with distinguishing between 'causal laws' and 'patterns of events' (Marcos-Cuevas, 2006).

Tsang and Kwan (1999, p.762) provide a summary of the three aspects of realism. First, it is focused on the structures and mechanisms as opposed to empirical events. Second, 'The structures and mechanisms are only contingently related to observable empirical events'. Third, it is always possible to generate knowledge via creative construction and critical testing of theories. Thus, in a constructivist approach, reality is created by both the researcher and the research participants (Ibrahim, 2013). This, according to Howell (2012), is founded on the phenomenological positions because this approach considers reality to be integrated with the integrations between subjective and objective perspectives. In relation to qualitative research the ontological perspective is constructivist, implying that the social factors are the result of interactions between peoples as opposed to a phenomena and it is separate from those constructing it (Bryman and Bell, 2015). 


\subsubsection{Epistemology}

According to Guba and Lincoln (1994, p.108), epistemology can be defined as 'the relationship between the knower or the would-be knower and what can be known', thus, explaining the relationship between the researcher and the people being researched and relating this to how one comes to know what they know (Creswell, 2013). The epistemological perspective is interpretative, as it emphasises exploring the social world by analysing how the world is interpreted by the actors within it. That taking a positivist view, the researcher is objective and his findings are considered what is true. The post-positivist view considers that findings which can be replicated are most likely to be true (Guba and Lincoln, 1994). In the constructive approach, it considers the findings to be created and developed as the research progresses (Ibrahim, 2013).

Each of these philosophical positions for inquiry share a common element among them which is 'human construction' (Guba and Lincoln, 1994). They each provide their own specific approaches demonstrating how they work together within a situational research project. This can be seen in the way the post-positivism perspective emphasises cause and effect, while the latter mentioned paradigms place greater emphasis on understanding the world in which a phenomenology occurs (Ibrahim, 2013).

\subsubsection{Constructivist method of inquiry}

Any of the approaches for inquiry could be selected for this research project in order to explore the phenomena occurring within the OCs under investigation. However, the real impact would become evident in the final results. Recently the constructivist approach has gained more credence among social-science methodologists (Ibrahim, 2013). However, the constructivist view takes the assumption that what is considered to be objective knowledge and truth ultimately results from the researcher's perspective (Schwandt, 1998). Moreover, it emphasises the phenomena of the research and considers both the data and its analysis as a combined result from the researcher and those researched, stemming from shared experiences and relationships (Charmaz, 2011). In light of the research objectives and the issues associated with uncovering culture it appears the constructivist paradigm was the most suitable in fulfilling the aims of this research, due to its focus on shared experiences and its interpretation of reality as being locally constructed (Howell, 2012).

\section{Research approach}

Two main research approaches used by researchers are inductive and deductive. This is heavily linked to the philosophical assumptions of the researcher (Saunders et al., 2009). The deductive approach tends to sit with the positivist paradigm, while the inductive tends to be utilised more as an option for interpretive research (Creswell, 2009). The deductive approach is advantageous for establishing casual relationships (Fisher, 2007). It particularly involves testing a theoretical position by utilising a research strategy for this purpose (Saunders et al., 2009). In a deductive approach, the researcher is independent of the phenomenon being studied (Ibrahim, 2013). Criticisms of this approach have been that it does not fit with many theoretical models and due to its tendency to require a strict methodology it does not allow freedom for alternative explanations (Ibrahim, 2013). 
Figure 3 Deductive approach

Theory $\longrightarrow$ Hypothesis $\longrightarrow$ Observation $\longrightarrow$ Confirmation/Rejection

This is particularly important in studies in the field of business and management or where human behaviour is a primary element (Ibrahim, 2013). The inductive approach however, is rooted in qualitative research (Saunders et al., 2009). In this approach, greater emphasis is given to individual interpretations and the experiences of the research participants. The inductive approach focuses on the relationship between theory and research, where the theory is generated from the research (Bryman and Bell, 2015). The inductive approach tends to be more flexible than the deductive approach, as it better facilitates for the researcher to make more informed decisions as to the research design and its strategies while taking into account limitations (Easterby-Smith et al., 2012). For these reasons, the inductive approach was selected for this research.

\section{Research design}

In the past, quantitative research has been labelled as 'hard' while social sciences have been considered 'soft' and associated with less precision and dependability (Miles and Huberman, 1994). However, criticisms of merely quantitative methods have emerged, which include: stripping variables of their context, excluding meaning and purpose, disjunction of outsider and insider approaches to study and inapplicability of general findings to individual cases (Miles and Huberman, 1994). These weaknesses of quantitative research can be significantly mitigated by utilising qualitative research. Furthermore, an important aspect of this is to ensure the researcher does not influence the phenomena, which is also a disadvantage of quantitative research (Miles and Huberman, 1994). This is particularly the case where an outsider approach can have very little meaning within the single view of researched groups or cultures. Qualitative research is confirmed to be useful for uncovering such insider views (Corbin and Strauss, 1990a). Although qualitative approaches are also not without criticism, it is important to consider the paradigms and their underlying assumptions.

In this research study, the aim is to explore OCs and how they can influence the success or failure of lean philosophy in SMEs in manufacturing industry. This topic has not previously been heavily researched. Thus, in line with Creswell's definition below, a qualitative approach has been selected. According to Creswell (2013), in qualitative studies much exploration needs to be done into the research problem as the variables are rather unknown and the general aim is to research the context that might shape the understanding of the phenomenon that is under investigation. According to Denzin and Lincoln (2011), it is important for qualitative researchers to conduct their research within their natural setting in order to interpret the phenomena in accordance with the meanings the research participants attribute to things (Javadi, 2013). Qualitative research tends to involve the use of a number of empirical materials such as observations, interview, focus groups and life stories (Javadi, 2013). 
Table 2 Characteristics of qualitative and quantitative research

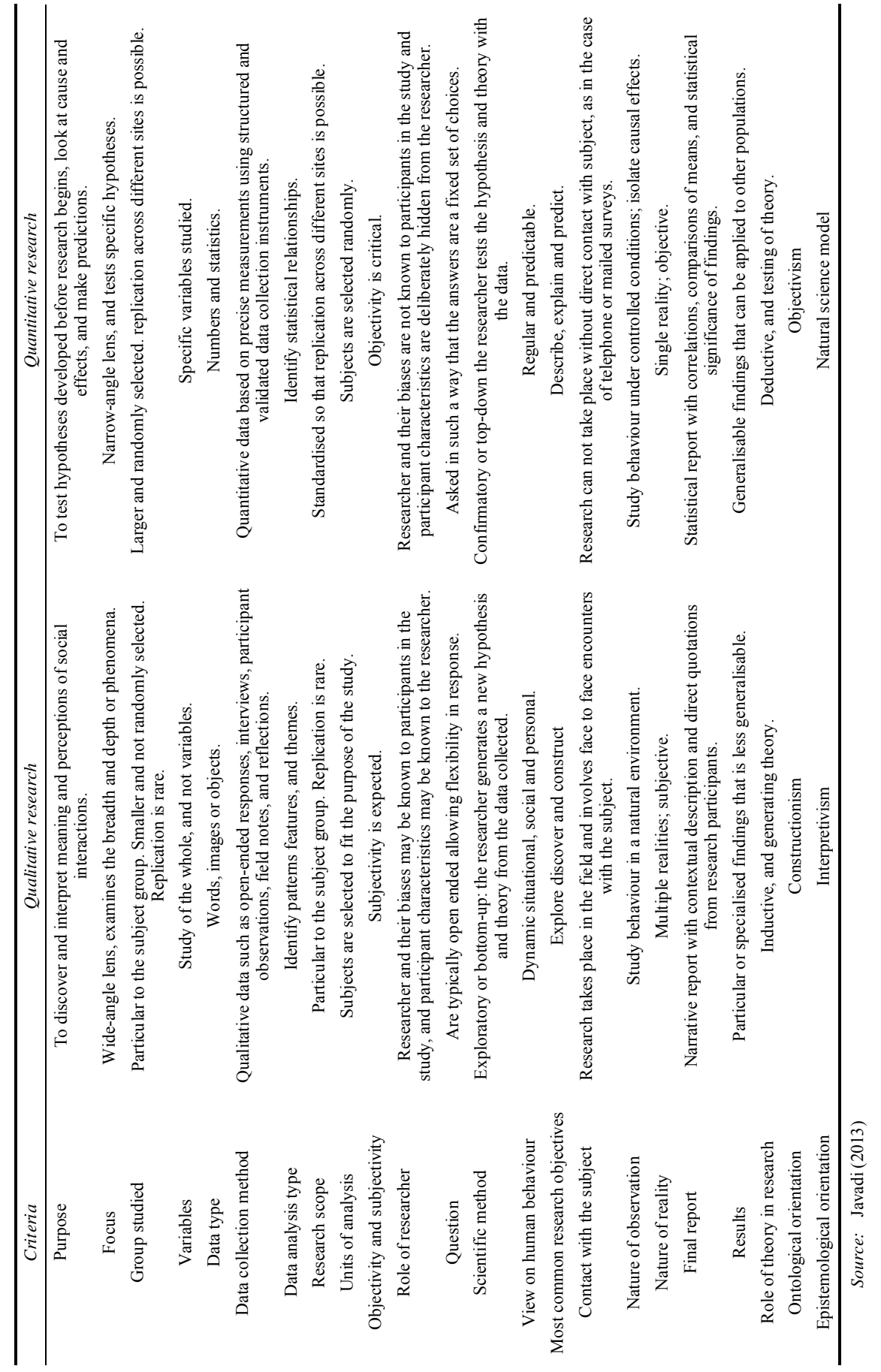


Figure 4 Inductive approach

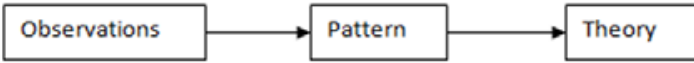

Creswell (2007, p.15) defines qualitative research as 'an inquiry process of understanding based on distinct methodological traditions of inquiry that explore a social or human problem'. This research puts together a complex but holistic image of analysis through words, and detailed accounts from participants within their natural setting (Creswell, 2007). Many researchers have made distinctions between qualitative and quantitative research as a result of their characteristics (Javadi, 2013). The most significant quantitative and qualitative characteristics are outlined in Table 2.

Qualitative research utilises a more descriptive method for gathering and interpreting information in order to understand the broader phenomenon (Javadi, 2013). There are numerous advantages to utilising a qualitative approach, in that it gives far more depth in terms of understanding the phenomenon. It helps to find answers to questions by studying a number of social situations and the individuals within that environment (Bruce and Berg, 2001). There is however, another perspective on qualitative research. Babbie (2015) suggests it is a suitable strategy for researching subtle nuances in the attitudes of people and their behaviours for the purpose of understanding the development of social processes over a longer period of time. Furthermore, more flexibility and greater validity are other associated advantages of qualitative research (Babbie, 2015). It also provides the researcher with a greater level of flexibility to identify numerous variables across a number of OC environments (Javadi, 2013). According to Audet and D'Amboise (2001) when the main objective is to improve knowledge about a phenomenon, qualitative research methods are normally favoured. Here, this research involves the study of OC and depends heavily on qualitative techniques as opposed to quantitative in order to understand the phenomenon.

\section{Research methodologies}

There are many strategies available to researchers to conduct their research. As the aim of this study is to build a theory and a framework as opposed to testing a theory, the choice of methodology most appropriate for this is the Grounded theory of Glaser and Strauss (1998). An action research approach was adopted to determine the factors that affect LI processes. As stated by Weber (2004), the main aim of research is to improve knowledge about particular phenomena. Moreover, there are many research strategies and methodologies mentioned in literature. In the following sections, the different research methodologies will be outlined.

\subsection{Case study}

An important aspect to consider is why the choice of grounded theory and not the 'case study' as a research methodology. If a case study were selected, then only one manufacturing company (SME) would be researched. However, by selecting grounded theory it opens the scope to including more manufacturing SMEs into the research 
sample (Javadi, 2013). Table 3 depicts the characteristics and contrasts between case study and grounded theory approaches.

Table 3 Characteristic of case study and grounded theory

\begin{tabular}{|c|c|c|c|}
\hline No. & Question & Case study & Grounded theory \\
\hline 1 & $\begin{array}{c}\text { What is the purpose of } \\
\text { the research? }\end{array}$ & $\begin{array}{l}\text { To examine a single 'case' in } \\
\text { depth in order to understand } \\
\text { the person or phenomenon }\end{array}$ & $\begin{array}{l}\text { To drive a theory that } \\
\text { links participants' } \\
\text { perspectives to general } \\
\text { social science theories }\end{array}$ \\
\hline 2 & $\begin{array}{l}\text { What is the nature of the } \\
\text { research process? }\end{array}$ & $\begin{array}{l}\text { Studies on bounded cases, and } \\
\text { focus on natural context }\end{array}$ & $\begin{array}{c}\text { Studies 'process' focus on } \\
\text { interactions }\end{array}$ \\
\hline 3 & $\begin{array}{l}\text { What are the methods of } \\
\text { data collection? }\end{array}$ & $\begin{array}{c}\text { Interactive fieldwork, formal } \\
\text { and informal interviews, and } \\
\text { some use of quantitative } \\
\text { measures. }\end{array}$ & $\begin{array}{l}\text { Draws from historical } \\
\text { records interviews, } \\
\text { observations, and } \\
\text { variable, multiple units }\end{array}$ \\
\hline 4 & $\begin{array}{l}\text { What are the methods of } \\
\text { data analysis? }\end{array}$ & $\begin{array}{l}\text { Interpretational search for } \\
\text { themes, structural search for } \\
\text { patterns in discourse, and } \\
\text { reflective rich portrayal of } \\
\text { participants views }\end{array}$ & $\begin{array}{l}\text { Concept oriented open } \\
\text { axial and selective coding } \\
\text { constant comparative } \\
\text { method }\end{array}$ \\
\hline 5 & $\begin{array}{l}\text { How are the findings } \\
\text { communicated? }\end{array}$ & $\begin{array}{l}\text { Analytical (objective) } \\
\text { narrative, and reflective } \\
\text { (literary) narrative }\end{array}$ & Analytical story \\
\hline
\end{tabular}

Source: Leedy (1997, Table 7.2, p.166).

One aspect which is important to note is that grounded theory can be utilised in conjunction with a case study (Javadi, 2013). It could be utilised as a mode of inquiry and unit of analysis for the case study. Table 6 also identifies some overlap between the characteristics; however, a case study approach would limit the research to one single organisation.

\subsection{Ethnography}

Ethnographic research in a methodological sense refers to studying the manner in which people interact (Gill and Johnson, 2010). In addition, it aims to study people's behaviour and their culture (Oates, 2009). This methodology offers insights about a group of people and provides the chance to observe and understand their environment (Boyle, 1994). In this mode of inquiry the researcher immerses themselves in the social setting for a longer span of time observing the behaviour and conversations between individuals and at times, asking questions (Fisher, 2007). Current research methods utilised to study culture include in-depth ethnographies at one end of the spectrum and at the other, pragmatic questionnaires (Cameron and Freeman, 1991). Both of these methods suggest studying culture, yet what they tend to discover is rather different (Allard and Anderson, 2005). The advantages however, of utilising a detailed ethnography method is that it does tend to provide in-depth information specific to the context, which can be useful in identifying paradoxes or any inconsistencies (Allard and Anderson, 2005).

However, the main disadvantage associated with ethnographic research is it requires a high level of participation from the researcher for the full extent of the data collection. The researcher is required to be a full-time group member as well as a researcher. In 
addition, the researcher needs to spend more time in the field in order to understand the culture under study (Collis and Hussey, 2013; Merriam and Tisdell, 2015; Oates, 2009). In addition, the reflexive nature of ethnographic research is a characteristic that implies that the researcher is part of the world under study and consequently affected by it (Boyle, 1994; Goulding, 2005). Also, it is difficult to gain access for long periods in the field (Punch, 2005; Bryman, 2008). In addition, the disadvantages to utilising this method is that it is generally extremely time consuming and the nature of the information does not easily enable comparisons to be made between cultures (Birkinshaw et al., 2011) Moreover, it does not facilitate making generalisations beyond the context the situation was researched in Cunliffe (2010), thus, rendering it an unsuitable approach for creating a framework.

\subsection{Cognitive mapping}

Cognitive mapping (also known as mental mapping) is a method that can be used to explore a person's beliefs about a topic as well as relationships that exist among the beliefs. Cognitive mapping 'is a process composed of a series of psychological transformations by which an individual acquires, stores, recalls, and decodes information about the relative locations and attributes of the phenomena in his everyday spatial environment' (Downs and Stea, 2011). Eden et al. (2009) define a cognitive map as:

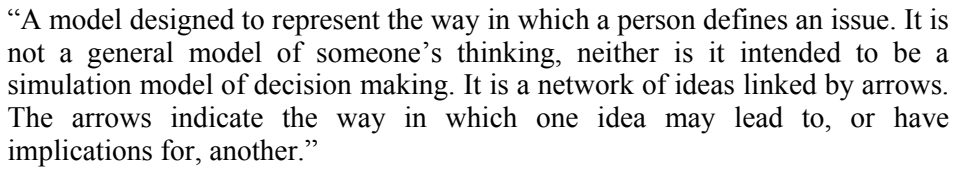

The disadvantages of cognitive mapping are the interviewer's ignorance, knowledge, misconceptions and biases are all encoded in the map (Kosko, 1992); it cannot deal with co-occurrence of multiple causes such as expressed by 'and' conditions, and 'if-then' cannot be coded as well (Schneider et al., 1998).

\subsection{Action research}

Action research is a strategy that allows practitioners to examine and improve their own working practices (Baskerville and Wood-Harper, 1996; Oates, 2009). It is intended to solve existing problems in the professional environment (Collis and Hussey, 2013). Collaboration is needed between the researcher and members of the field of work under investigation in order to identify the problem and provide the solution (Bryman, 2012). Action research tends to be used for prompting conscious change within a somewhat controlled environment (Collis and Hussey, 2013). In this approach, the participants and the researcher collaborate on a problem to find a solution (Coghlan and Brannick, 2014). This is an inquiry mode generally utilised to help solve organisational issues by dealing with those experiencing the problems (Ibrahim, 2013). Some main weaknesses associated with action research is the assumption that the behaviour of a person is only able to be changed by testing them, and moreover, it tends to require set timelines and is usually expensive to conduct over the full research period (Fisher, 2007). The researcher in this approach is concerned with performing actions, not only describing or observing. Therefore, it is 'research into action' - planning for change, performing the change, 
reflecting on what happened then starting another cycle [Oates, (2009), p.155]. It aims to investigate and bring change to phenomenon [Punch, (2005), p.160]. This approach requires the researcher to work in the field of study and involves a continuous cycle of improvement (Partington, 2002). Alderfer and Smith (1982) stated that when action research is part of the contract between researcher and organisation then the microcosm group also plays a key role in the design and conduct of data feedback.

\subsection{Phenomenology}

Phenomenology is a qualitative research method propounded by Husserl (1970) that studies people's experiences (Merriam and Tisdell, 2015). It fits small-scale research best and gives descriptions reflecting the complexity of the social world (Denscombe, 2010). It has a 'focus on the experience itself' and is concerned about the experiences of our lives [Merriam and Tisdell, (2015), p.24]. However, participants in this study may lack the required experience, which may prevent the researcher from gathering the required data. Also, in phenomenology studies, the words of information are considered the one valid source of data (Goulding, 1998). However, in this research multiple data sources, which include interviews, observation and published reports were gathered and applied.

\subsection{Grounded theory}

Grounded theory is a research methodology that aims to create a theory from data that have been systematically researched and analysed (Javadi, 2013). This methodology was originally used by (Glaser and Strauss, 1967), undertaking an observational field study with patients who were soon facing death. They defined grounded theory as 'the discovery of theory from data' [Glaser and Strauss, (1967), p.1]. According to Golden-Biddle and Locke (2007), grounded theory has been the most often utilised qualitative methodology in social science research. Its popularity can be attributed to: first, its suitability for developing new theory or new insights form old theory; second, it generates theory which stems from what the research participants consider important; finally, it is able to expose micro-management processes in complex situations and environments (Locke, 2001). Goulding (1998) suggests grounded theory is particularly useful for making new discoveries, thus its usefulness for theory generation. Furthermore, Locke (2001) and Goulding (2005) also consider grounded theory as useful where there is a clear lack of integrated theory in an area of literature.

According to Stern (1980), 'grounded theory becomes an answer were other methodologies did not work well enough, especially in the sensitive dependant variable fields within the health science and business and management' [Stern, (1980), p.30]. Goulding (1988) suggests that grounded theory becomes particularly useful when a subject matter has been rather ignored or dealt with superficially. Corbin and Strauss (2014) also provide an example of when and when not to use grounded theory. They suggested that if one wants to know if a drug trial is more effective than another in that case it would be more useful to use a double-blind clinical trial as opposed to grounded theory. However, if one wanted to know what it is like to participate in a drug study, then grounded theory or some other form of qualitative research approach would be most suitable. Thus, it is particularly useful for theory generation from social processes and 
actions which have been through situations from people who have experience in the phenomenon being studied (Goulding, 1998).

The main feature of this approach is to develop categories that highlight the data and develop the categories to create a framework (Silverman, 2006). This approach has been most commonly utilised for qualitative research in social sciences since its inception (Altheide and Johnson, 1994). Grounded theory tends to be inductive, as it seeks out the interpretations and perspectives of those in the situation under research (Charmaz, 2011). A differentiating factor of grounded research from the other inquiry modes is in its investigation into the questions of 'why' and 'how' in a way that is grounded in the data rather than deduced logically (Jones, 2009). Another great advantage to grounded theory is that in allows the researcher more flexibility and to utilise interviews as a data collection tool (Glaser and Strauss, 1967).

\section{Methodology chosen for the research}

While ethnographic or a case study method might have been suitable for this research, grounded theory grounded theory better facilitates a suitable methodology and mode of analysis, (Ibrahim, 2013). This is particularly due to its suitability for researching deeply into the area of OC and its influence on lean philosophy and its suitability for generating a theory (Goulding, 1998). Robson (2002, p.165) describes "Grounded theory based research as one of the influential qualitative methodologies besides case studies and ethnography." Furthermore, it provides the benefit of allowing the researcher to explore deeply into an unknown area such as human behaviour (Robson, 2002). Howell (2012) suggests grounded theory emphasises the interpretation of a situation and it is these interpretations which result in theory building" [Ibrahim, (2013), p.123]. Considering the need of the topic at hand to enable the generation of a theory and framework, grounded theory presents itself as the most suitable method (Strauss and Corbin, 1998). In addition to this, it allows for a broader range of data sources to be utilised which enhances the opportunity to collect various perceptions and viewpoints on the topic being researched, (Glaser and Strauss, 1967).

The history of grounded theory begins at its inception in 1967 and founded by Glaser and Strauss. It was published in their book Discovery of Grounded Theory. Glaser and Strauss were originally influenced by the ideas of Dewey (1922), Mead (1934) and Blumer (1969). Glaser and Strauss suggested that scientific truth lies from both observing and emerging consensus within a group of observers to make sense of what has been observed (Suddaby, 2006). The authors aimed to build abstract theoretical explanations for social processes which became revolution at the tome challenged many ideas (Charmaz, 2011). Some of the main ideas challenged include; beliefs that qualitative methods were unsystematic, the separation research phases involving data collection and analysis, ideas that qualitative research is merely a 'precursor' to more rigorous quantitative research, the notion that qualitative research was incapable of creating a theory (Charmaz, 2011).

Glaser and Strauss (1967) were pioneers in providing written guidance for conducting systematic qualitative data analysis with clear analytic procedures and research strategy (Ibrahim, 2013). Although later, Glaser and Strauss took different paths with their own distinctive versions of grounded theory (Javadi, 2013). In (1990) Strauss together with Corbin wrote a book called Basics of Qualitative Research, 1st ed. announcing their 
perspective and their own version of grounded theory. Strauss and Corbin's (1994) and Corbin and Strauss (1990b) paradigmatic position relates to an interpretative approach as opposed to Glaser $(1978,1992)$, and Denzin and Lincoln (1994) lean more towards a post positivist position, (Ibrahim, 2013). In 1992, Glaser provided further elaboration on grounded theory in his new book Basics of Grounded Theory Analysis and in this he responded to version Strauss and Corbin published challenging their ideas, (Javadi, 2013). In (1998) Strauss and Corbin then launched their 2nd edition providing more details on their coding system as a response to Glaser's challenges in 1992. After 1998 numerous other researchers and writers have added to the grounded theory debate proposing new perspectives which include, Locke (2001), Heath and Cowley (2004), Charmaz (2011) and Corbin and Strauss (2008). These developments make it very important for researchers to make clear which version of grounded theory they are utilising. For the purpose of this research the Strauss and Corbin (1998) approach towards grounded theory has been selected and the rationale for this is discussed below.

\section{Data analysis}

The sections below will outline the data analysis procedures from simultaneous, concurrent data collection, content analysis and grounded theory coding analysis.

\subsection{Simultaneous and concurrent data collection}

In grounded theory, data collection and analysis occur concurrently, enabling the research to being analysis as soon as the data emerges (Corbin and Strauss, 1990a). According to Corbin and Strauss (1990b, p.6) "data collection and analysis systematically enables the research process to capital all potentially relevant aspects of the study as soon as they are perceived." Thus, the data is analysed looking for all the possible interpretations from the very beginning (Goulding, 1998). To ensure nothing is missed it is recommended that the researcher should start analysing the first set of data for ideas and leads (Ibrahim, 2013). The benefit of this is it provides the researcher with cues on what to include in the next stage of interviews (Goulding, 1998). Thus, demonstrating the process of data collection and analysis in concurrent as opposed to linear and conceptual theorising occurs from the inception of the research process (Boychuk Duchscher and Morgan, 2004).

\subsection{Constant comparative method}

The constant comparative method is utilised by the researcher to create concepts from the data gathered, which involves coding and analysing at the same time (Taylor and Bogdan, 1998). This method "combines systematic data collection, coding and analysis with theoretical sampling in order to generate theory that is integrated, close to the data an expressed in a form clear enough for further testing" (Scott et al., 1993).

The constant comparative method involves four stages:

- $\quad$ comparing incidents applicable to each category

- $\quad$ integrating categories and their properties

- $\quad$ delimiting the theory 
- writing the theory [Glaser and Strauss, (1967), p.105].

During these four stages the researcher is continuously sorting through the data collection, analysing and coding the data and reinforcing theory creation by theoretical sampling (Kolb, 2012). Therefore, incidents that are deemed to be similar are grouped together under concepts (Corbin and Strauss, 2008). Constant comparison is designed to help the researcher in creating a theory which is fully integrated and consistent with the data, which has also, be a source of validity in grounded theory research (Silverman, 2006).

\subsection{Content analysis}

Content analysis was selected as a method for analysing the data gathered in the present research. According to Krippendorff and Weber (1987), content analysis uses a set of procedures that ensures valid inferences. It helps to tell the story of the data through analysing the content of the raw data, the themes and main ideas. In this study, a list of aspects had already been highlighted in the initial conceptual framework. Therefore, a technique of pattern matching was applied (Yin, 2009); according to Yin, pattern matching strengthens the internal validity. Further, the analysis allowed more aspects to emerge from the data and hence new factors were identified and the initial framework revised. Another advantage that justified the selection of content analysis is the possibility to go back to the original raw data and check for missing codes or aspects or wrong categorisation (Woodrum, 1984). Woodrum (1984) also maintains that content analysis has the potential to study attitudes, organisations and human relations. However, Yin (2009) argues that in case study research much of the analysis depends upon the author's own style of rigorous thinking. This makes the analysis process prone to researcher bias; therefore, measures were undertaken to overcome this issue in the present research.

\subsection{Coding procedures}

Corbin and Strauss (2008) refer to the analysis of data as coding. This involves three different levels of analysis, open coding, axial coding and selective coding, which are discussed below.

\subsubsection{Open coding}

Open coding can be defined as, 'the analytic process through which concepts are identified and their properties and dimensions are discovered in data' [Strauss and Corbin, (1998), p.101]. Throughout this process the data are analysed very closely and compared against each other to detect similarities or differences (Strauss and Corbin, 1998). Open coding is the first stage of grounded theory analysis which according to Strauss and Corbin is to 'open up the inquiry' (Strauss and Corbin, 1998). During this phase the data is broken down into smaller segments, reviewed and developed into concepts and categories (Strauss and Corbin, 1998). Open categories refer to concepts generated from the data which help to describe the phenomena which is held important by the participants (Glaser and Strauss, 1967). 
Properties are the narrowed down attributes of a category and dimensions refer to the location or positioning of a property across a continuum (Strauss and Corbin, 1998). A number of techniques are available in order to assist to open up the line of enquiry, such as basic questions like Who? What? When? Where? Why? and How? Also available is temporal questioning such as frequency and duration or timing (Javadi, 2013). The 'flip-flop' technique refers to the consideration of opposite characteristics, and 'red flags' refers to when an interviewee mentions a situation, which according to them never occurs or always occurs, requiring the researcher to determine any possible exceptions (Javadi, 2013). Open coding can be done by line-by-line analysis, sentence or paragraph analysis or also by going through an entire document and looking at it as a whole (Strauss and Corbin, 1998).

\subsubsection{Axial coding}

Axial coding refers to the process of linking themes and issues together based on a relationship and are usually done on an inductive and deductive basis (Strauss and Corbin, 1998). In this process, according to Corbin and Strauss (1990b), is to put the information together in a new way by identifying links between categories and subcategories. This is done via the coding paradigm which includes conditions, action and consequences (Strauss and Corbin, 1998). However, Glaser (1992) criticises this by instead utilising selective coding, which codes around a core category with a greater emphasis on theoretical coding (Stern, 1994). Glaser suggests that coding for solely what is in the data and allowing for emergence then verification will occur automatically (Stern, 1994). Although according to Dey (1999), Strauss and Corbin emphasise the importance of implementing the 'doing paradigm' in axial coding and the paradigm includes most of Glaser's (1978) 18 coding families. Essentially Glaser puts theoretical coding after selective coding, but Strauss puts axial coding before selective coding. If the coding paradigm is intended to replace the theoretical codes, it is unclear as to why Strauss and Corbin changed the original order (Walker and Myrick, 2006). Walker and Myrick (2006) suggest that Strauss and Corbin aim to make the procedure more obvious, albeit somewhat more complicated.

\subsubsection{Selective coding}

This refers to selecting one category as the core concept and linking all other categories to this particular one. Glaser's (1978) work is brought together using theoretical coding and Strauss and Corbin (1994) use selective coding. Theoretical coding can be defined as using theoretic codes 'to conceptualise how the substantive data may relate to each other as hypothesis to be integrated into a theory' (Glaser, 1978). These come from cues in the data that help to bring the pieces together. Selective coding, according to Strauss and Corbin (1998), is 'the process of integrating and refining the theory'. In their process, the core category relates to all other categories. Selective coding is similar to axial coding, only that integration happens at a more abstract level on analysis (Corbin and Strauss, 1990b). Strauss and Corbin's selective coding revolves around selectively coding around a core category (Walker and Myrick, 2006). 


\section{Data gathering methods}

Data analysis in qualitative research deals with words, and the meanings implied by them (Miles and Huberman, 1994). The analysis of the information gathered is done by discovering categories and their interrelationships. The program utilised for this in this research was NVIVO software for coding. The ability to identify categories and interrelationships is referred to as 'theoretical sensitivity'. Theoretical sensitivity is the 'ability to recognise what is important in data and to give it meaning' [Corbin and Strauss, (1990b), p.46]. Certain techniques can be utilised to help enhance this theoretical sensitivity.

\subsection{Issue-focused investigation}

In order to obtain a better understanding of the nature of OCs within SMEs in the manufacturing industry, this study will focus on three main criteria: First, to expose the implied components of culture from an insider's perspective; second, to be mindful of structural aspects of the culture for example sub-cultures (Babbie, 2015); and third, to facilitate comparisons to be made among individuals and research settings (Birkinshaw et al., 2011). The use of these criteria has enabled an issue-focused interview style that is founded upon phenomenological orientation leading to successive comparison (Birkinshaw et al., 2011). In addition, these focus groups and observations were utilised to provide triangulation of results. Issue-focussed investigation allows for the fulfilment of the above criteria. Due to the nature of culture being omnipresent, this makes it difficult for people to often reflect and describe when asked a question about it directly (Dey, 1999). Therefore, in order to draw this out it often requires a response to a stimulus requiring respondents to interpret something, which is naturally done according to their own cultural basis as opposed to that of the researcher (Sackmann, 1991).

The choice of stimulus is also important. It should present a specific type of context yet be broad enough to allow freedom of interpretation (Willis et al., 2007). This is important because when people are presented with something unusual they tend to access categories that already exist in their minds enabling them to process, understand and interpret (Denzin and Lincoln, 2011). The implied components of the culture are then usually made apparent in the interpretations provided by the respondents. Furthermore, issue-focussed investigation is particularly suitable because, by presenting them with a stimulus with a specific context, the respondents then tend to access the same library of knowledge already existing in their minds (Sackmann, 1991). This helps to uncover their framework about a specific issue. This then enables comparisons of the interpretations to uncover individual opinions from cultural beliefs that are common among the group (Willis et al., 2007). It is possible this can also help bring up subcultures (Denzin and Lincoln, 2011). The specific issues selected should be ones that are relevant to the participants and their roles within the organisation.

It is important for the selected participants to have some knowledge about the topic at hand so they can reliably discuss it as opposed to just guessing (Plummer and Young, 2010). The issue/stimulus selected can be considered relevant for the organisational participants when they can provide three examples relating to this situation. The comparisons of the answers can reveal commonalities, themes or clear differences. Culturally-based notions are mostly described in a consensual way as opposed to facts (Bryant, 2009). Thus, when presented with something unusual, people then seek out 
means of interpretation which pre-exist in their mind from their understanding of the organisation's reality. Issue-focussed investigation needs to be conducted cleverly to ensure the participants do not realise that particular issue is under investigation (Sackmann, 1991). Otherwise, the responses can end up skewed or biased (Patton, 2014). In a longitudinal study, such biases may reveal interesting aspects, but it is too ambitious for a short-term study. Thus, the questions asked were issues focussed in accordance with Sackman's (1991) grounded theory approach:

- $\quad$ Tell me about an example you have seen LI work well?

- Tell me about a situation where LI has not worked well?

\subsection{Phenomenological orientation}

The phenomenological orientation has its focus on the insider's perspective and their beliefs and concepts, ideas of the OC and life within it. It places emphasis on the insider's view of what is considered important and relevant within that setting (Goulding, 2005). The researcher will put aside their own assumptions so these do not interfere or influence the respondent's answers. The emphasis is to allow the respondents to gradually unravel their own experiences. In order for the researcher to avoid making judgments based on their own beliefs, these should first be made clear (Annells, 1996). The interview procedure in a phenomenological orientation is close in style to an in-depth or intense interview. This usually consists of a longer introduction and a period of becoming better acquainted. This also gives the researcher the chance to gently introduce the subject of the discussion (Srubar, 1998). The aspects that are brought up by the respondent are the points that are then delved into with more detail. In doing so, the researcher is better able to explore together with the respondent and identify the cognitive frameworks that come up (Bryant, 2009). This process of an established dialogue also enables the researcher to check they have understood the respondent's point of view correctly. This can be done by the researcher mentally answering the question in their head before the respondent has a chance to check their own accuracy (Goulding, 2005). This type of research requires not only flexibility but a rapport to have been well-established between the researcher and the respondent because for in-depth issues to come to light the interviewee needs to feel comfortable, safe and that a mutual trust exists (Goulding, 2005).

\subsection{The combination of issue focus and phenomenological orientation}

There are some advantages to employing both an issues-focussed investigation and a phenomenological orientation. The latter is much unstructured and broad; however, the issue-focussed investigation works to narrow the scope giving more structure to the process. Furthermore, the researcher takes their cue from the respondents as to the most important aspects to be further explored (Sackmann, 1991). The respondents were asked to mention the aspects of lean principles they considered most important in their organisation (for example). They were also asked to explain why these were the most important. This enabled a cross-comparison of the responses of the individuals, increasing reliability. In the phenomenological phase, the researcher ensures all aspects of the factors brought up by the respondents are investigated (Bryant, 2009). Therefore, this particular approach by Sackmann (1991) was been selected for this research. 


\section{Data collection}

The tools generally employed to study culture consist of observations, structured, semi-structured or in-depth interviews, both with individuals and focus groups (Pearse and Kanyangale, 2009). Each of these qualitative tools have their own strengths and weaknesses. The types of methods generally utilised for studying culture in organisations are either a deductive mode of inquiry, which adopts an outsider's perspective, or an inductive approach, which is from an insider's perspective (Pearse and Kanyangale, 2009). Hypotheses are then established according to the relevance to the specific questions asked and tested. Therefore, the researcher is the onlooker and culture is considered a controllable variable (Sackmann, 1991).

For the purposes of this study an inductive approach was selected. When an inductive approach is utilised, the inquiry is conducted from the inside to better understand occurrences within the environment being researched (Golden-Biddle and Locke, 2007). In this case, the information gained is specific to that particular context and is not able to be generalised. It is possible for concepts or hypotheses to emerge and this inductive approach treats culture as an integral part of the organisation (Golden-Biddle and Locke, 2007), this is why it was chosen for this study and fitted within the constructivist approach.

\subsection{The use of the literature review}

According to Corbin and Strauss (1990b), there are two types of literature, technical and non-technical literature, and both are of equal usefulness and can be used at the same points in grounded theory analysis procedures. Technical literature, which includes theoretical and philosophical papers as well as other empirical studies, can be used as background resources for comparison against the results of grounded theory (Corbin and Strauss, 1990b). Non-technical literature includes other resources such as reports, manuscripts, and diaries and can be used to supplement the gathered data or as primary data (Corbin and Strauss, 1990b).

In this study, previous literature, including theories and empirical studies relating to lean culture, were reviewed to explore current thinking in this area of research. Although the review of the previous literature did not lead to any hypotheses, it helped to gain insight into the data, which made the grounded theory methodology the appropriate approach for this study. Moreover, the technical literature was used as background resources for comparison against the results. Nontechnical literature was used as well for the purpose of supporting several emerging issues resulting from the empirical study.

\subsection{Interviews}

Interviews are open-ended questions gaining in-depth responses about people's experiences, perceptions, opinions and feelings and knowledge (Taylor, 2005). Structured interviews have been criticised for their reliability, because similar to questionnaires, respondents tend to conform to the culture of the researcher as opposed to the culture being researched (Pearse and Kanyangale, 2009), although this can be mitigated if they are developed on a foundation of knowledge gained within the research setting (Patton, 2014). In depth interviews/unstructured interviews are often utilised to help expose culturally-based values (Patton, 2014). The key here is, the researcher should not 
introduce cultural values, but instead use open-ended questions and the insider's own language, which helps evoke responses revealing the aspects of everyday life in that cultural setting (Creswell, 2013).

The weaknesses associated with in-depth interviews are: first, the process of trying to separate an individual's opinion and cultural information; and second, ensuring objectivity and reliability of the information (Taylor, 2005). It is important for the researcher to be conscious of their own biases and influences in the information-gathering process (Patton, 2014). Objectivity in the information analysis phase can be created by utilising different people to analyse the same information (Patton, 2014).

It is important however, for the assisting analysts to also have an understanding of the research setting from an insider's perspective (Sackmann, 1991). For this research semi-structured interviews were also utilised. The advantage with semi-structured interviews is that they ensure certain topics are covered making them more comparable and easier to obtain reliable qualitative information (Patton, 2014). Furthermore, it allows the interviewee to bring up other aspects that they also consider relevant or important, which is key to grounded theory methodology (Miles and Huberman, 1994). For the interviews, the participants selected from each company included managers, production engineers and factory floor employees. It is considered important to include all levels of employees in the interview process as all are equally important to LI as well as the overall OC (Angelis et al., 2011). The semi-structured interview in this research was utilised to explore the factors that affecting LI in terms of OC, by using an issue-focused investigation approach (Sackmann, 1991).

\subsection{Observations}

Participant observation involves 'fieldwork descriptions of actives, behaviours, actions, conversations, interpersonal interaction, organisational or community process, or any other aspect of observable human experience' (Taylor, 2005). This generally involves spending an extended period of time being immersed in the research setting. An advantage with observations is that they do not require prior knowledge and the concepts are established inductively (Cook and Yanow, 1993). However, it is a very timeconsuming process and can be very expensive. Teams of researchers can be utilised, although this can create issues because each person does discrete as opposed to replicative work, which creates validity and reliability problems (Taylor, 2005). Furthermore, researchers have the challenge of looking beyond their own cultural biases and interpreting and reporting information about another culture (Patton, 2014). During the observations, the interactions between colleagues and managers were observed. Also, interactions between colleagues themselves, participant behaviour during the interview, reports and any other printed materials were also observed. Also, their working style, how they process systems, the kinds of relationships between them and even notice boards and the layout of the offices and factory and their emotions and moods will all be noted (Taylor, 2005).

\subsection{Focus groups}

Focus groups are another tool for revealing cultural assumptions, according to Schein (1985), "because the group provides the stimulus to bring out what is ordinarily hidden." 
This data gathering tool was first developed in the 1920s and has since been utilised in social sciences (Fontana and Frey, 1994). Although focus groups may not always achieve the same depth as one-to-one interviews, they are still very useful (Fontana and Frey, 1994). Focus groups are considered to be useful particularly in exploratory studies, which aim to gain a greater understanding of a social context (Fontana and Frey, 1994). The group dynamic can create clearer distinction of individual opinions from cultural beliefs and reveal taboos (Sackmann, 1991).

A particular advantage associated with focus groups is the opportunity for participants to hear other's views, which can generate varied responses as the discussion develops (Kolb, 2012). Focus groups also serve to validate any ideas the researcher may be wishing to confirm (Jones and Noble, 2007). Furthermore, it helps to provide an opportunity for understanding group dynamics which might affect individual's perceptions (Jones and Noble, 2007). Researchers need to be skilled in order to draw out the more hidden aspects while also being aware of their own cultural biases (Taylor, 2005). The researcher conducted the focus groups in each company in a meeting room, and they were also being recorded to enable accurate revision and analysis of the data. For this research the researcher organised groups of around eight to 12 participants and time frame was set between one to two hours (Gray, 1998). They were conducted face to face with everyone together in a meeting room and snacks and beverages provided.

The main premise of the focus groups for this research was to utilise an action research approach in that the participants refined the aspects, named the categories while providing the data under each category, thus, it reflected the ideas and perceptions of what is important to the employees.

\title{
10 Rigour in the research
}

\author{
"A trustworthy study is one that is carried out fairly and ethically and whose \\ findings represent as closely as possible the experiences of the respondents." \\ [Padgett, (2008), p.184]
}

Between qualitative and quantitative research there are many differences with respect with evaluation (Guba and Lincoln, 1989). Quantitative research is evaluated on the basis of reliability and validity [Lietz and Zayas, (2010), p.190]. Mason (1996) suggests that reliability, validity and generalisability vary in terms of measurement of the quality and rigour of the study and its potential to be applied to broader situations. Validity can be defined as 'whether you are observing, identifying, or measuring what you say you are' [Mason, (1996), p.24].

In contrast, LeCompte and Goetz (1982) refer to reliability and validity by distinguishing between 'external reliability' and 'internal reliability'. External reliability refers to the extent to which a study is able to be replicated. Some recommended strategies for duplicating qualitative research is to take on a comparable role taken on by the original researcher (Bryman and Bell, 2015). Internal reliability refers to if there are numerous observers or just one, and the agreement among the observers of what they are exposed to. Internal validity refers to how well the observations made by the researcher match the theories they comprise (Bryman and Bell, 2015).

According to LeCompte and Goetz (1982), internal validity is a key strength available to qualitative research, especially where the researcher spends a high period of duration within the research environment thus helping to ensure the strength of compatibility 
between concepts developed and observations. External validity refers to the extent to which the results are able to be generalised over various social situations (Bryman and Bell, 2015). According to LeCompte and Goetz (1982) this is the most problematic area for qualitative research, as it tends to utilise smaller sample populations and is used for case study purposes. However, Guba and Lincoln (1994) propose a further method for evaluating qualitative research based upon four criteria:

1 credibility, which refers to internal validity

2 transferability, referring to external validity

3 dependability, paralleling reliability

4 confirmability, which refers to objectivity.

Table 4 Criteria for ensuring rigour in qualitative research

\begin{tabular}{lccc}
\hline Rigour-critical & Criteria for rigour & Research strategy & Techniques to insure rigour \\
\hline Credibility & Truth value & Field notes/memo & Purposeful/theoretical \\
& & sampling \\
& Tape recorder & Negative/deviant case \\
& Thematic log & Constant comparison \\
& Auditing transcript & Member checking \\
Transferability & & Triangulation \\
& Applicability & Data display & Audit trial \\
& & & Purposeful/theoretical \\
& & Simultaneous literature & Thick description \\
Dependability & review & Negative/deviant case \\
& & Field notes/memo & Member checking \\
& & Tape recorder & Triangulation \\
& & Thematic log & Audit trial \\
& & Auditing transcript & \\
& & Reflexivity & Audit trial \\
\hline
\end{tabular}

Source: Liamputtong (2009)

Their reasoning for challenging the notion of merely assessing reliability and validity is due to its assumption that an absolute count of a social situation is possible (Bryman and Bell, 2015). Guba and Lincoln (1994) however, hold that more than one absolute truth is possible in multiple situations. Therefore, this emphasis on multiple accounts for social realities is particularly relevant when considering the criteria of credibility in qualitative research. Furthermore, if a number of possible accounts of an aspect of a social situation are possible, it is the credibility of the account that will ultimately determine how acceptable it is. This is essentially where respondent validation becomes an important factor. Triangulation is also another technique that is recommended to deal with this issue (Bryman and Bell, 2015). 
Since qualitative research is more subjective, reliability and validity are in compatible with it. Consequently, validity and reliability are not are not suitable measurement in qualitative research, because the measurement change position to the positivist approach instead of the approach of interpreted [Angen, (2000), p.379; Liamputtong and Ezzy, (2009), p.21]. Guba and Lincoln (1989) and Lincoln and Guba (1985) have developed four criteria as mentioned above. These guiding principles are used to evaluate qualitative research and should not be rules for using validity and reliability inside positivist research [Carpenter and Suto, (2008), p.150; Lietz and Zayas, 2010]. These criteria are listed in Table 4.

\subsection{Credibility}

"Interpretations must be authentic and accurate to the descriptions of the primary participants." (Drisko, 1997)

Reliability and authority of the research is judged by its credibility [Liamputtong and Ezzy, (2009), p.21]. The idea here is the description should be fitted with the explanation [Tobin and Begley, (2004), p.391]. Credibility should fit between how the researcher represents their viewpoint and what the participants said so as to control the risk of reactivity and bias (Padgett, 2008). Lietz and Zayas (2010, p.191) define reactivity as: 'The potential for the researcher to exert an impact on the participants thereby changing the findings of the study.' The way the researcher behaves or asks questions during the interview can raise reactivity.

To achieve credibility in the current research two main strategies were adopted:

1 Applying selection techniques to the participants regarding their knowledge, characteristics and their experience. Moreover, theoretical sampling gives credibility to the research (Carpenter and Suto, 2008).

2 When the interpretation and description can be recognised by the participants, i.e., 'when the multiple realities held by participants are represented as accurately and adequately as possible' [Liamputtong and Ezzy, (2009), p.21]. Therefore, it can be achieved (Johnson and Waterfield, 2004).

\subsection{Transferability}

Transferability is the capability to apply the findings of the research to other settings, situations, contexts, events, individuals or groups (Padgett, 2008). In other words, it is the degree to which finding can be applicable to other settings or contexts [Carpenter and Suto, (2008), p.149]. In-depth descriptions about the phenomenon being studied should enable other researchers to understand whether the findings are applicable to fit into other settings and contexts (Devers, 1999; Lietz and Zayas, 2010).

\subsection{Dependability}

Dependability (auditability) is the degree to which the study is documented to allow other researchers to trace and follow the research process (Padgett, 2008). Dependability is confirmed when the research process is well documented and tractable [Tobin and Begley, (2004), p.392]. Therefore, it can be compared to reliability [Liamputtong and 
Ezzy, (2009), p.22]. Dependability thus means to make sure that the findings fit to the derived data [Carpenter and Suto, (2008), p.150].

The idea behind dependability is based on repeatability. Consequently, it is concerned whether the researcher is capable or able to obtain the same result from the findings of the research if he/she observes the same phenomenon or more than one. However, a researcher cannot obtain the same output from the research because he/she is measuring two or more than two different things. Therefore, the researcher should give in detail a description of the changes that take place and how these changes influenced the way the research was approached. For example Lietz and Zayas (2010, p.196) state, "one way of addressing the need to make decisions and changes along the way is to provide detailed documentation throughout the research project." Therefore, 'keeping an audit trail and engaging in peer debriefing' are two strategies that shape dependability [Lietz and Zayas, (2010), p.196].

The audit trail is a written, detailed report of the research process that should describe what exactly happened during the research. Here, a journal of observations and significant event was maintained throughout the research. This journal suggested by Coghlan and Brannick (2014) to record reflections and thoughts on observed events and also to write down any comments made and to support a timeline for the significant events that occurred during the research process. This provided an opportunity to observe and record all teams in the firms and their actions that were relevant to the research. The use of a journal facilitated triangulation of events and observations on aspects related to the OC.

In addition, peer debriefing is used to consult other experts (colleagues) in qualitative research approaches, discuss and explain procedures and decisions to obtain feedback that can enrich the quality of the research (Padgett, 2008).

\subsection{Confirmability}

Confirmability is the ability and capability of other researchers to confirm the research result (Lincoln and Guba, 1985). It confirms that the results from the research are linked to the data (Padgett, 2008). It can also be defined as the degree to which result are specified by respondents and not by the perspective of the researcher [Lincoln and Guba, (1985), p.290]. Therefore, confirmability can be achieved by presenting the data from the research and the analysis steps leading to the result.

\subsection{Respondent validation}

This refers to the process where the researcher reports back to the population from which the research was gathered an account of the findings. Thus, ensuring sufficient correlation between their result and the perspectives of the research population (Bryman and Bell, 2015). This also gives the research the opportunity to identify aspects of the observations that might be incongruent to the social reality. It is important to realise that this can at times prompt defensive reactions or even for information to be made 'off the record' from research participants. This is sometimes due to personal accounts leaving individuals too vulnerable (Bryman and Bell, 2015). Another criticism involving this approach is whether research participants are appropriate to validate the analysis of a researcher as the findings are designed for a completely different audience (Bryman and 
Bell, 2015). Therefore, while this approach might achieve a corroborative response from the research participants, the researcher will still be required to move forward through concept development and theories. Thus, there needs to be clear boundaries regarding research results that participants have control over and which material is crucial for academic reasons (Silverman, 2006).

\subsection{Triangulation}

The term triangulation was coined by Webb et al. (1966) and refers to 'using more than one method or source of data in the study of social phenomena' [Bryman and Bell, 2015, p.397]. It was established as a method for the development of measures to create a higher level of confidence in research findings. Ethnographers will often utilise this method to cross check their observations with interview questions to mitigate any misunderstandings (Bryman and Bell, 2015).

Because qualitative research tends to involve the study of smaller groups with greater emphasis on depth as opposed to breadth, the contextualisation and uniqueness of the findings is generally high (Silverman, 2006). Therefore, researchers are encouraged to adopt 'thick description' of a culture, which involves creating a comprehensive database for others to make their own judgements for the transferability of the results (Bryman and Bell, 2015).

In terms of dependability, Guba and Lincoln (1994) propose that detailed records of each research phase are kept to enable ease of auditing the research gathering and findings. Although this is often troublesome with qualitative research, which tends to gather particularly large datasets. Furthermore, Guba and Lincoln (1994) encourage the use of the authenticity criteria. This includes attributes such as fairness in terms of representation of viewpoints, discerning how well the research enables a better understanding of the social situation, its ability to create a better appreciation for the perspectives within the social situation, its ability to prompt change among its members, and how well it empowers the members to make appropriate changes (Bryman and Bell, 2015). Thus, the practical outcomes of the research are emphasised.

Denzin (2017) located four kinds of triangulation, which were all applied and adopted to this research.

1 Using multiple methods such as observation and in-depth interview together in the research (Padgett, 2008). This drives the validity of the research, as the same results are alignment and confirmed through different methods in the research.

2 Researcher triangulation, which refers to there being more than one researcher conducting the research either by collecting data, observing and analysis (Winston and Heiko, 1990).

3 Source triangulation or data triangulation, by using multiple quotations, collecting data from many different locations and involving multiple participants [Carpenter and Suto, (2008), p.153; Winston and Heiko, (1990), p.238].

4 The last kind is called theoretical triangulation, using different theoretical frameworks within the same research or study in order to interpret the result from the study (Padgett, 2008). 


\subsection{Inter-rater reliability}

Cohen (1960) discussed that according the psychology area there is some situation in clinical-social-personality, it occasionally occurs that the best useful level of measurement degree attachable in nominal sealing. In this research, assessment of the inter-rater reliability took place in early stage of the analysis process. The procedure is that having two or more judges independently to determine the significance, degree and sample stability of agreement (Rashid, 2010). Gwet (2002) provide that evaluation of the extent of the agreement between two or more raters is commonly used in social, medical and behavioural sciences. He gave an example of a reliability experiment where two raters (A and B) classify $\mathrm{N}$ subjects into one or two potential responses, i.e., (1 or 2) (yes or no); the categories are suggested as being disjointed (no overlap) (Rashid, 2010). Table 5 shows how Gwet's categories are modelled.

Table 5 Distribution of subjects

\begin{tabular}{lccc}
\hline \multirow{2}{*}{ Rater $B$} & \multicolumn{4}{c}{ Rater $A$} \\
\cline { 2 - 5 } & Yes & No & Total \\
\hline Yes & A & b & B (yes) $=\mathrm{a}+\mathrm{b}$ \\
No & $\mathrm{C}$ & $\mathrm{d}$ & $\mathrm{B}(\mathrm{no})=\mathrm{c}+\mathrm{d}$ \\
Total & $\mathrm{A}(\mathrm{yes})=\mathrm{a}+\mathrm{c}$ & $\mathrm{A}(\mathrm{no})=\mathrm{b}+\mathrm{d}$ & $\mathrm{N}$ \\
\hline
\end{tabular}

Source: Gwet (2002) adapted from Rashed (2010)

where a: total number of subjects classified as (yes) units by both raters; b: total number of subjects classified as (yes) units by rater B and as (no) units by rater A; c: total number of subjects classified as (yes) units by rater A and as (no) units by rater B; and d: total number of subjects classified as (no) units by both raters.

Table 6 The degree agreement between the raters

\begin{tabular}{lc}
\hline K value ranges & Degree of agreement between raters \\
\hline $0.08-1.00$ & Almost perfect \\
$0.60-0.79$ & Substantial \\
$0.40-0.59$ & Moderate \\
$0.20-0.39$ & Fair \\
$0.00-0.19$ & Slight \\
$\leq 0.00$ & Poor \\
\hline
\end{tabular}

Source: Huddleston (2003) and Rashed (2010)

There are two measures commonly used in inter-rater reliability, namely Cohen-Kappa (K) and percentage of agreement (\%) (Gwet, 2002; Hsu and Field, 2003). Their formulations are shown below:

1 Cohen's Kappa method

$$
\mathrm{K}=(\mathrm{F} 1-\mathrm{F} 2) /(\mathrm{N}-\mathrm{F} 2), \mathrm{K}=0.00 \text { to } 1.00
$$




$$
\begin{aligned}
& \text { where } F 1=a+d \\
& F 2=[(a+b)(a+c)+(b+d)(c+d)] / N \\
& N=a+b+c+d
\end{aligned}
$$

The degrees of agreement indicated by Kappa are given in Table 6.

2 Percentage of agreement method

The formula of percentage of agreement is $[(\mathrm{a}+\mathrm{d}) / \mathrm{N}] * 100 \%$.

Table 7 shows the level of agreement between raters according to their percentage of agreement.

Table 7 Percentage level of agreement between the raters

\begin{tabular}{lc}
\hline Percentage ranges & Level of agreement between raters \\
\hline $91-100$ & Very high \\
$81-90$ & High \\
$71-80$ & Moderate \\
$61-70$ & Fair \\
$51-60$ & Slight \\
$\leq 50$ & Poor \\
\hline
\end{tabular}

Source: Huddleston (2003) and Rashed (2010)

\section{Framework validation}

Expert opinion was used in this research. According to the Oxford Dictionary (2014), the definition of an expert is 'a person who is very knowledgeable about or skilful in an area', or a person 'having or involving a great deal of knowledge or skill in a particular area'. The reason behind using an expert panel's opinion and knowledge is to add trustworthiness about the findings of the research, which enhances the robustness of the outcome as well as guides the researcher's perspective (Achanga et al., 2006). The experts should be knowledgeable in the subject matter addressed and discussed in the research (Fink, 2005).

\section{Research process phase}

The research process was divided into three phases as shown in Figure 5. The following sub-section will explain each phase. 
Figure 5 Research process phases (developed by researcher)

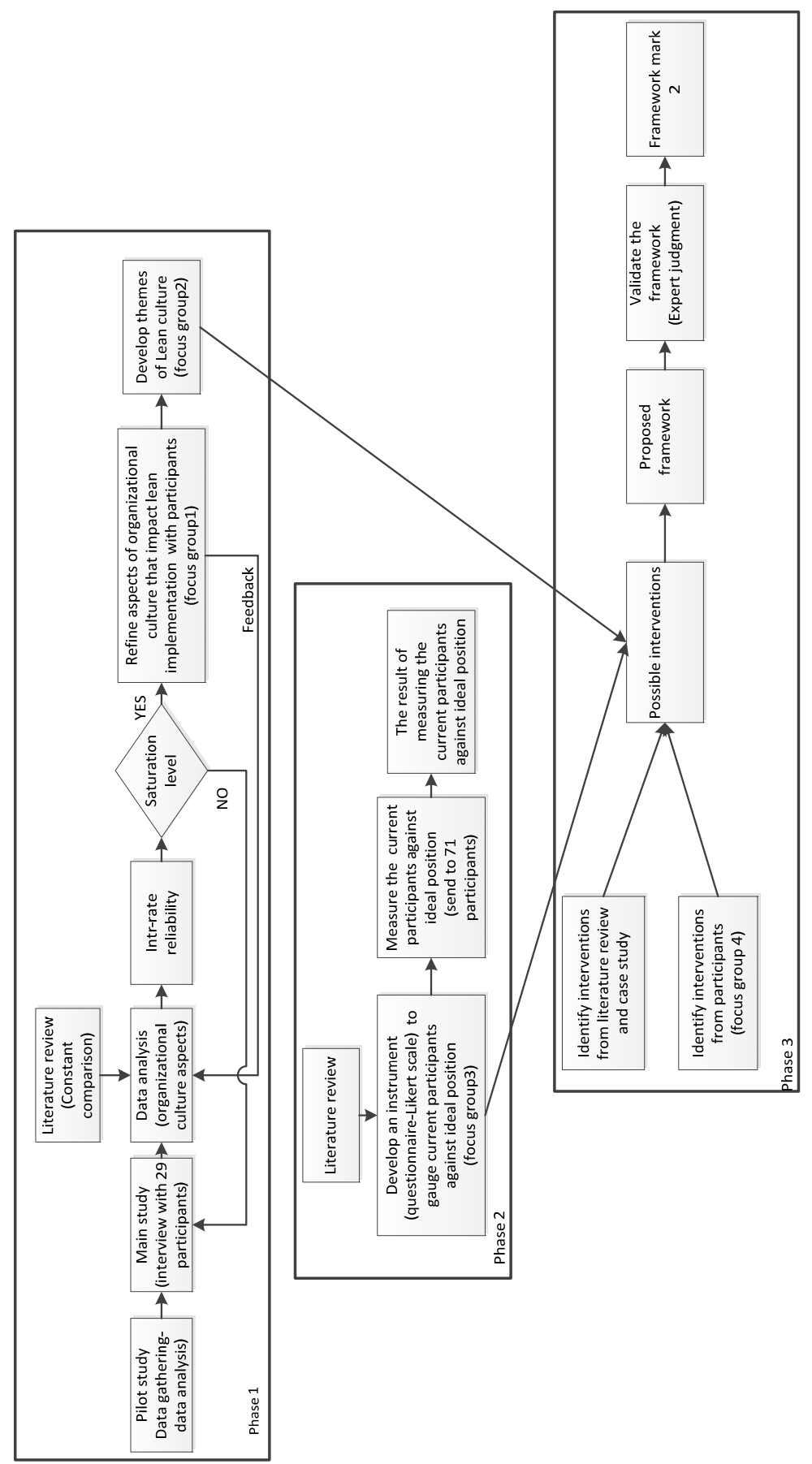




\subsection{Phase one}

To begin this phase, a literature review was conducted in order to increase the researcher's understanding of the scope of research on the topic of the enablers and inhibitors of LC in SMEs; much of the literature pointed to OC as being an important factor as to why LI was largely unsuccessful (Angelis et al., 2011). Therefore, this prompted the researcher to further explore what has been studied regarding lean philosophy and OC to identify enablers and inhibitors in this area. The literature review has also helped to broaden the researcher's scope of knowledge and theories pertaining to the topic.

In relation to the literature review the researcher has also utilised Scopus, ABI/INFORM Collection, EBSCO, IEEE, and Website Science, ScienceDirect, Emerald, SAGE, Inderscience and Taylor and Francis as sources for OC, enablers and inhibitors of LI overall and specifically for SMEs. After the review, the researcher commenced a pilot study. Two SMEs in the manufacturing sector were selected in which interviews with managers and employees were conducted. From these results, the researcher was able to gather a list of OC enablers and disablers for lean practices in SMEs. The researcher then compared this list with the information found in the literature review.

The new data that emerged from the pilot study identified aspects which appeared from the perspectives of the participants not the researcher (Strauss and Corbin, 1998). The data was analysed with NVIVO software. The pilot study also provided the opportunity to test the questions provided in the seven interviews conducted in the organisation to help to reduce bias and research errors in terms of types of questions provided. An important task is for all researchers to make known their perceptions and thoughts on the issues and topics before research formally begins. This is crucial to mitigating bias in the research process (Annells, 1996).

Then, the research moved to the main study to conduct 29 interviews including the pilot study interviews. Then, all the interviews were analysed and compared with the literature review. Tests of inter-rater reliability were utilised in this stage to evaluate the results. When the results reached the saturation level, the researcher moved to the first focus group to refine the aspects that were analysed from interviews. The final step in first phase was focus group two, the purpose for this was to involve the participants in aggregating the aspects into high level themes and locate all the themes within Schein's model.

\subsection{Phase two}

The second phase was marked by the beginning of developing an instrument to gauge the current perception of the participants against the ideal position of the themes. This involved the participants from focus group three and the literature review to design the assessment. This drove a joint review of the assessment results and their relevance to the OC. In order to gauge the OC more specifically, an assessment tool based on the OC theme description was participatively developed with the participants. A Likert scale was used for this questionnaire to gauge current perception of participants against the ideal positions. A series of short statements relating to each of the seven themes were developed with the team in focus group three to describe an ideal position of the required OC. Statements for each theme indicated the ideal position OC for LI. The participants assessed their perception of the OC by gauging how close they perceived they were to 
ideal position of the seven themes, reflecting the ideal position of the OC for manufacturing SMEs. The questionnaire was sent to the participants by email. A total of 71 responses were returned. All the scores were added together and averaged to produce a group perspective of the participants' position against an ideal position for OC.

\subsection{Phase three}

In this phase, the researcher conducted selections of possible interventions from literature review, work place and from focus group four. The selection of interventions were based on themes and ideal positions that were generated from focus group three and from the literature review. It was during this phase that the framework development began. Here, the researcher selected the proposed interventions and systematically related this to themes and validate those relationships by expert judgments as the final phase of the research (Corbin and Strauss, 1990b).

\section{Framework development}

According to Glaser (1978), the aim of grounded theory is to create a conceptual theory that includes a pattern of behaviour which is both relevant and problematic for the participants. The continual resolving is 'designated by a category called the core category' [Glaser, (1978), p.199]. With regard to the role of grounded theory in terms of theory development, the methodological boost provided by grounded theory to qualitative research is in the development of theory, which necessitates developing concepts and their linkages to identify variations characterising the phenomenon (Strauss, 1987). In addition, theoretical sampling is a process that is often used alongside the coding process (Kolb, 2012). Whilst open coding (aspects) is taking place, sampling has a clear direction and it is systematic.

From the interviews, all the results were constantly compared to the information found in the literature review. During the focus group, the process of themes became more structured in order to validate relationships within the data and the agenda becomes more deliberate in order to integrate the findings within the themes to achieve data saturation (Corbin and Strauss, 2008). Data saturation refers to the stage when the data collected in the research is now redundant (Bogdan and Biklen, 2007). This is necessary to ensure enough data has been collected to reflect the perspectives of the research participants (Kolb, 2012).

From a research perspective, grounded theory can promote sensitivity, prompting of research questions, pointing to direct theoretical sampling and assists in providing valid outcomes (Corbin and Strauss, 1990b). It is these benefits which according to McGhee et al. (2007) assist the researcher to give a justification for the research and avoid any conceptual and methodological obstacles (Ibrahim, 2013). According to Strauss and Corbin (1998), 'this method aims to understand the nature of human activity within organised setting and supports the construction of theory from the qualitative data gathered' [Ibrahim, (2013), p.141]. Thus, theory is constructed from the themes, and data within each theme.

A series of short statements relating to each of the themes were developed with the team in focus group three to describe an ideal position of the required OC. Finally, a 
suitable set of interventions was developed that would be applicable to SME manufacturing in the form of a strategic action plan, based on empirical examples of interventions designed to develop a lean culture to facilitate LI. The proposed interventions comprised a series of linked management actions in the form of a framework to shift the lean culture of the SMEs closer to an ideal position of a desired lean culture. The desired outcome from the research is an outline of a framework of interventions designed to create the conditions of an OC that will facilitate lean culture. The framework can be planned and put together fitting centrally around the theory that has been generate.

Figure 6 Schein's model of OC

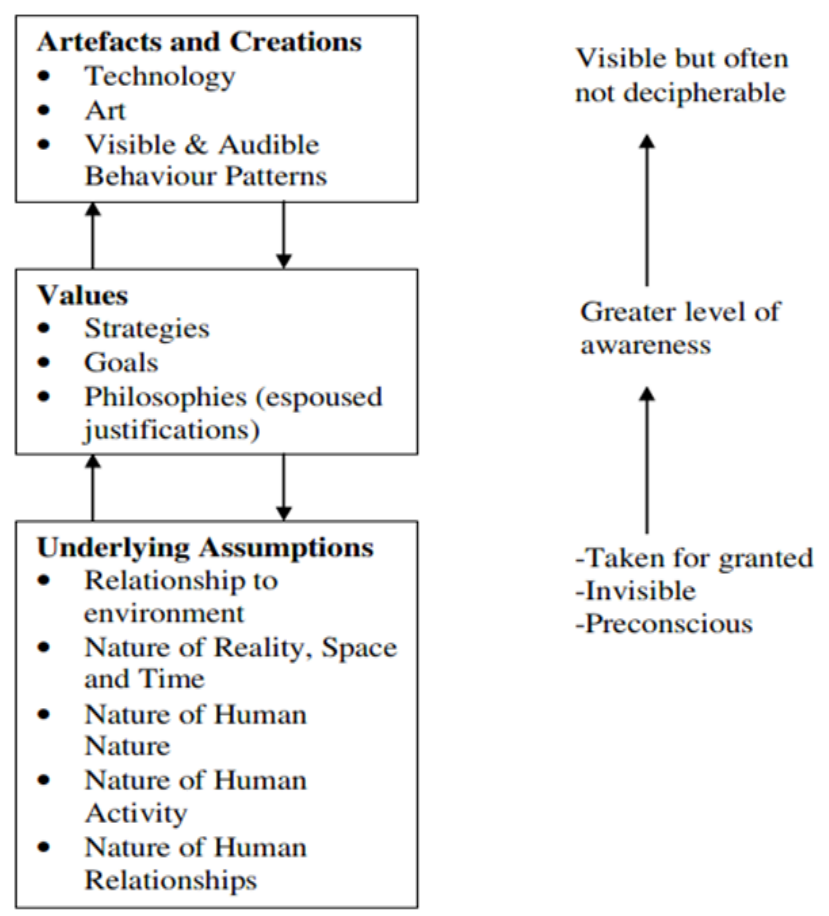

\section{Conceptual framework}

A useful framework to understand lean culture in terms of OC is Schein's model (1984). Schein (1984) modelled the existence of 'artefacts, values and beliefs and the behaviours which are commonly shared and accepted by members in the organisation' [Detert et al., (2000), p.851]. Schien's model suggests that OC is established from a group working together and developing patterns as they collaborate to solve problems and ensure organisational survival (McLaughlin et al., 2010). His model is comprised of three levels. The first level is artefacts which are the objects and elements which can be seen or experienced such as the company building and logos, the processes, communication, etc. The second level is espoused values that are comprised of the principles and standards 
within an organisation belonging to their employees; these describe what is considered important by the organisation. Finally, the third level is underlying assumptions, which refers to beliefs, thoughts and feelings. Schein's model emphasises the way in which artefacts and values can expose things regarding underlying assumptions (Schein, 1990). Schein's models have proved to be powerful in understanding and measuring OC. Schien's model helps in understanding OCs at different levels such as artefact, espoused values and basic underlying assumptions by fully describing the organisational behaviours as norms and relationships between group members. It is found to be more about observing than collecting data. An organisation could be judged by observation of people and their dress code. Schein's model is shown in Figure 6.

\section{Conclusions}

This chapter has outlined the ontological and epistemological approaches adopted as constructivist, and the research methodology selected for this research was grounded theory as well as a participative action research approach with an inductive stance. The advantages and disadvantages of quantitative and qualitative research are discussed with the latter being the choice for this research. The various methodological inquiry modes are also discussed which include, case study, ethnographic research, action research and grounded theory. Grounded theory was selected as the most appropriate inquiry mode for qualitative research, as it is highly recognised for its ability to generate theory from the data (Strauss and Corbin, 1998). Furthermore, Sackmann's approach (1991) is discussed and applied, which combines both issues-focussed and phenomenological focussed research as a highly suitable approach for researching OC. Semi-structured interviews, observations, literature review and focus groups were selected as data gathering methods. The research was conducted and analysed in three phases. The contribution of this study to the body of knowledge on LI is expected to be significant. Considering the nonexistence of LI by leveraging aspects of OC studies within the SMEs manufacturing context by developing a methodology to surface aspects of OC.

The research methodology followed is primarily qualitative. The main weaknesses of qualitative research are potential bias from the participants and from the researcher as well. The research followed a grounded theory methodology. This bias nature can affect the validity and reliability of results. To mitigate these weaknesses, the author took many actions. By applying action research. In addition, one of the actions is to use of a variety of methods in the data collection phase. Moreover, the researcher considered in this research to use the credibility, transferability, dependability and confirmability. The qualitative nature of the research required a sufficient understanding of the suitable methods to be used when collecting data. The author used face-to-face interviews, focus group and observation. The information captured from different sources was triangulated to minimise bias. In addition, the researcher has used Sackmann approached during data gathering. Moreover, the author triangulated the data collected by means of semistructured with different experts from different organisations. In addition, the questionnaires used in this research to gauge current perception of participants against ideal position. After collecting and analysing the required data from different sources, the key findings were summarised and presented to the participants to reduce the researcher's bias. Moreover, it been observed that no previous research has used a grounded theory 
inside action research for LI within SMEs manufacturing sector. In addition, the research contributes to knowledge concerning aspects of OC that facilitate LI. This knowledge is transdisciplinary and adds to the domains of LI, OC and lean culture. The researcher has deployed a grounded participative methodology, within a 'live' SMEs manufacturing sector teams to surface key aspects of lean culture. The research can be a live experimental approach to organisational development. This approach adds to the theoretical knowledge of organisational development for transformational change as the research is participative; it is well placed in its potential for developing theory that will be relevant to practice (Huxham and Vangen, 2003). This participative approach to developing knowledge of the members' perceptions of lean culture and on creating LI capability from an insider perspective contributes develop framework. Moreover, due to the diversity of data-collection sources used, this study added new insight to the inhibitors faced by SMEs which may not enable them to implement lean, and addressed the source of those inhibitors. Finally, the framework does not currently exist in the literature, which facilitate LI by leveraging aspects of OC relating to SMEs presented here thus represents a unique effort in LI.

The findings of this study are limited in terms of generalisability to SMEs, as the study mainly considered SMEs in manufacturing sector. There is also a lack of information and published studies regarding SMEs manufacturing industries in terms or methodologies; further, there is an absence of research regarding LI within SMEs

countries, and this meant that it was not possible to compare the findings with those of other researchers. In this study, a semi-structured interview technique was adopted, along with other data collection methods. Semi-structured interviews and focus group may lead to bias, however, different techniques were employed to keep this bias limited.

For future research, the main opportunity for further research is in observing the impact of the methodology implemented over time on the development to surface the aspects of OC that effected LI.

\subsection{Future work}

In the future, an empirical study will be carried out in order to explore the OC that inhibit LI within SMEs manufacturing firms. Furthermore, a framework of LI will be developed by leveraging aspect of $\mathrm{OC}$ will be explored.

\section{Acknowledgements}

This research presented in this article is a part of the research project of A Framework to Improve Lean Implementation by Leveraging Organisational Culture.

\section{References}

Achanga, P., Shehab, E., Roy, R. and Nelder, G. (2006) 'Critical success factors for lean implementation within SMEs', Journal of Manufacturing Technology Management, edited by Saad, S. Vol. 17, No. 4, pp.460-471, doi: 10.1108/17410380610662889.

Alderfer, C.P. and Smith, K.K. (1982) 'Studying intergroup relations embedded in organizations', Administrative Science Quarterly, Vol. 27, No. 1, p.35. 
Alkhoraif, A. and Mclaughlin, P. (2017) 'Organisational culture -enablers and inhibitors factors for the effective implementation of lean within SMEs', International Journal of Lean Thinking, Vol. 8, No. 2, pp.65-96.

Alkhoraif, A. and McLaughlin, P. (2018) 'Lean implementation within manufacturing SMEs in Saudi Arabia: organizational culture aspects', Journal of King Saud University - Engineering Sciences, Engineering Sciences. doi: 10.1016/j.jksues.2018.04.002.

Alkhoraif, A. and Mclaughlin, P. (n.d.) 'Organisational culture aspects that facilitate lean implementation: a pilot study', Int. J. Agile Systems and Management Agile Systems and Management, Vol. X, No. Y.

Allard, F. and Anderson, E. (2005) 'Ethnography', Encyclopedia of Social Measurement, Vol. 1, No. 4, pp.833-843.

Altheide, D. and Johnson, J. (1994) 'Criteria for assessing interpretive validity in qualitative research', in Handbook of Qualitative Research, pp.485-499, Sage Publications, Inc, Thousand Oaks, CA, US.

Angelis, J., Conti, R., Cooper, C. and Gill, C. (2011) 'Building a high-commitment lean culture', Journal of Manufacturing Technology Management, Vol. 22, No. 5, pp.569-586.

Angen, M. (2000) Evaluating Interpretive Inquiry: Reviewing the Validity Debate and Opening the Dialogue, SAGE Publications.

Annells, M. (1996) 'Grounded theory method: philosophical perspectives, paradigm of inquiry, and postmodernism', Qualitative Health Research, Vol. 6, No. 3, pp.379-393.

Audet, J. and D'Amboise, G. (2001) 'The multi-site study: an innovative research methodology', The Qualitative Report, Vol. 6, No. 2, pp.1-18.

Babbie, E. (2015) The Practice of Social Research, Wadsworth Cengage Learning, London.

Baskerville, R.L. and Wood-Harper, A.T. (1996) 'A critical perspective on action research as a method for information systems research', Journal of Information Technology, Vol. 11, No. 3, pp.235-246.

Birkinshaw, J., Brannen, M. and Tung, R. (2011) 'From a distance and generalizable to up close and grounded: reclaiming a place for qualitative methods in international business research', Journal of International Business, Vol. 42, No. 5, pp.573-581.

Blaikie, N. (2009) Designing Social Research, 2nd ed., Polity Press, Cambridge.

Blumer, H. (1969) 'Fashion: from class differentiation to collective selection', The Sociological Quarterly, Vol. 10, No. 3, pp.275-291.

Bogdan, R. and Biklen, S.K. (2007) Qualitative Research for Education: An Introduction to Theories and Methods, No. 3, Pearson A \& B.

Boychuk Duchscher, J.E. and Morgan, D. (2004) 'Grounded theory: reflections on the emergence vs. forcing debate', Journal of Advanced Nursing, Vol. 48, No. 6, pp.605-612.

Boyle, J. (1994) 'Styles of ethnography', Critical Issues in Qualitative Research Methods, Vol. 2, pp.159-85, SAGA publication, London.

Bruce, B. and Berg, M. (2001) Qualitative Research Methods for the Social Sciences, SAGA publication, London.

Bryant, A. (2009) 'Grounded theory and pragmatism: the curious case of Anselm Strauss', Forum Qualitative Sozialforschung/Forum, Vol. 10, No. 5.

Bryman, A. (2008) Social Research Methods, Oxford University Press, pp.69-75, doi: 10.4135/ 9781849209939.

Bryman, A. (2012) Social Research Methods, Social Research, SAGE Publications, London, doi: $10.4135 / 9781849209939$.

Bryman, A. and Bell, E. (2015) Business Research Methods, Oxford University Press, New York.

Cameron, K. and Freeman, S. (1991) 'Cultural congruence, strength, and type: relationships to effectiveness', Research in Organizational Development, Vol. 5, pp.5-23-58, JAI Press. 
Carpenter, C. and Suto, M. (2008) 'Qualitative research for occupational and physical therapists: a practical guide - Google scholar', The Canadian Journal of Occupational Therapy, Vol. 77, No. 1, p.6, Ottawa.

Charmaz, K. (2011) Grounded Theory Methods in Social Justice Research, SAGE Publications, London.

Coghlan, D. and Brannick, T. (2014) Doing Action Research in your Own Organization, Sage, London.

Cohen, J. (1960) 'A coefficient of agreement for nominal scales', Journal of Educational and Psychological Measurements, Vol. 20, No. 1, pp.37-46, Google Scholar.

Collis, J. and Hussey, R. (2013) Business research: A Practical Guide for Undergraduate and Postgraduate Students, Palgrave Macmillan, London .

Cook, S.D.N. and Yanow, D. (1993) 'Culture and organizational learning', Journal of Management Inquiry, Vol. 2, No. 4, pp.373-390.

Corbin, J. and Strauss, A. (1990a) Basics of Qualitative Research: Grounded Theory Procedures and Techniques, Sage, London.

Corbin, J.M. and Strauss, A. (1990b) 'Grounded theory research: procedures, canons, and evaluative criteria’, Qualitative Sociology, Vol. 13, No. 1, pp.3-21, doi: 10.1007/BF00988593.

Corbin, J. and Strauss, A. (2008) 'Basics of Qualitative Research (3rd ed.): Techniques and Procedures for Developing Grounded Theory, SAGE Publications, Inc, Newbury, 2455 Teller Road, Thousand Oaks, California 91320, USA, doi: 10.4135/9781452230153.

Corbin, J. and Strauss, A. (2014) Basics of Qualitative Research: Techniques and Procedures for Developing Grounded Theory, SAGE Publications, London .

Creswell, J.W. (2007) Qualitative Inquiry and Research Design, Chapter 4, SAGE Publications, London .

Creswell, J.W. (2009) Research Design: Qualitative, Quantitative, and Mixed Methods Approaches, Research Design Qualitative Quantitative and Mixed Methods Approaches, doi: 10.1007/s13398-014-0173-7.2.

Creswell, J.W. (2013) Research Design: Qualitative, Quantitative, and Mixed Methods Approaches, SAGE Publications, London.

Cunliffe, A.L. (2010) 'Retelling tales of the field', Organizational Research Methods, Vol. 13, No. 2, pp.224-239, doi: 10.1177/1094428109340041.

Denscombe, M. (2010) The Good Research Guide for Small-Scale Social Research Projects, Psychological Science, 4th ed., p.356, Saga, London.

Denzin, N. (2017) The Research Act: A Theoretical Introduction to Sociological Methods, Routledge, Saga, London.

Denzin, N. and Lincoln, Y. (1994) Handbook of qualitative research. SAGE Publications.

Denzin, N. and Lincoln, Y. (2011) The SAGE Handbook of Qualitative Research, Sage, London.

Detert, J.R., Schroeder, R.G. and Mauriel, J.J. (2000) 'A framework for linking culture and improvement initiatives in organizations', Academy of Management Review, Vol. 25, No. 4, pp. $850-863$.

Devers, K. (1999) 'How will we know 'good' qualitative research when we see it? Beginning the dialogue in health services research', Health Services Research, Vol. 34, No. 5, pp.1153-88.

Dewey, J. (1922) 'Education as politics', New Republic, Vol. 32, No. 409, p.409.

Dey, I. (1999) Grounding Grounded Theory: Guidelines for Qualitative Inquiry, Academic Press, Saga, London.

Dick, B. (2006) 'Grounded theory: a thumbnail sketch', Action Research Resources, Vol. 25, No. 6, pp.1-19, doi: 10.1109/DATE.2008.4484729.

Downs, R.M. and Stea, D. (2011) Cognitive maps and spatial behaviour: process and products', in The Map Reader, pp.312-317, John Wiley \& Sons, Ltd, Chichester, UK. 
Drisko, J. (1997) 'Strengthening qualitative studies and reports: standards to promote academic integrity', Journal of Social Work Education, Vol. 33, No. 1, p.185.

Easterby-Smith, M., Thorpe, R. and Jackson, P.R. (2012) Management Research, SAGE Publications, London.

Eden, C., Ackermann, F., Bryson, J.M., Richardson, G.P., Andersen, D.F. and Finn, C.B. (2009) 'Integrating modes of policy analysis and strategic management practice: requisite elements and dilemmas', Journal of the Operational Research Society, Vol. 60, No. 1, pp.2-13.

Fink, A. (2005) Conducting Research Literature Reviews: From the Internet to Paper, 2nd ed., London.

Fisher, C. (2007) Researching and Writing a Dissertation: A Guidebook for Business Students, Pearson Education, New York.

Fontana, A. and Frey, J. (1994) 'The art of science', in The Handbook of Qualitative Research, pp.36-76, Saga, London.

Gill, J. and Johnson, P. (2010) Research Methods for Managers, Sage, London.

Glaser, B. (1978) Theoretical Sensitivity: Advances in the Methodology of Grounded Theory, Saga, London.

Glaser, B. (1992) Basics of Grounded Theory Analysis: Emergence vs. Forcing, Mill Valley, Sociology Press, Calif.

Glaser, B. and Strauss, A. (1967) 'The discovery of grounded theory', Strategies for Qualitative Research, Weidenfeld, London.

Glaser, B. and Strauss, A. (1998) Grounded Theory: Strategien Qualitativer Forschung, pp.53-84, Sage, Bern.

Golden-Biddle, K. and Locke, K. (2007) Composing Qualitative Research, 2nd ed., Sage Publications, Inc., London.

Goulding, C. (1998) 'Grounded theory: the missing methodology on the interpretivist agenda', Qualitative Market Research: An International Journal, Vol. 1, No. 1, pp.50-57.

Goulding, C. (2005) 'Grounded theory, ethnography and phenomenology', European Journal of Marketing, Vol. 39, Nos. 3/4, pp.294-308.

Graham, B. and Thomas, K. (2008) 'Building knowledge - developing a grounded theory of knowledge management for construction', 7th European Conference on Research Methodology for Business and Management Studies, Vol. 6, No. 2, pp.169-176.

Gray, R. (1998) Organisational Culture and the Psychological Contract: A Review of the Literature, Kumpania Consultancy.

Guba, E. and Lincoln, Y. (1989) Fourth Generation Evaluation, Sage, London.

Guba, E. and Lincoln, Y. (1994) 'Competing paradigms in qualitative research', in Handbook of Qualitative Research, pp.105-117, Saga, London.

Gwet, K. (2002) 'Kappa statistic is not satisfactory for assessing the extent of agreement between raters', Statistical Methods for Inter-Rater Reliability Assessment, Vol. 1, No. 6, pp.1-6.

Heath, H. and Cowley, S. (2004) 'Developing a grounded theory approach: a comparison of Glaser and Strauss', International Journal of Nursing Studies, Vol. 41, No. 2, pp.141-150.

Hesse, M.B. (1980) Revolutions and Reconstructions in the Philosophy of Science, Harvester Press, London.

Howell, K. (2012) An Introduction to the Philosophy of Methodology, Sage, London.

Hsu, L.M. and Field, R. (2003) 'Interrater agreement measures: comments on Kappa n, Cohen's Kappa, Scott's $\pi$, and Aickin's $\alpha$ ', Understanding Statistics, Vol. 2, No. 3, pp.205-219.

Huddleston, J. (2003) An Evaluation of the Training Effectiveness of a Co-Fidelity Multiplayer Simulators for Air Combat Training, Cranfield University.

Husserl, E. (1970) The crisis of European Sciences and Transcendental Phenomenology: An Introduction to Phenomenological Philosophy, Evanston, Northwestern University Press. 
Huxham, C. and Vangen, S. (2003) 'Researching organizational practice through action research: case studies and design choices', Organizational Research Methods, Vol. 6, No. 3, pp.383-403.

Ibrahim, U. (2013) Investigating the Effects of Corporate Governance of Banks in Nigeria: A Grounded Theory Approach, Plymouth University.

Javadi, S. (2013) Performance Management in Higher Education: A Grounded Theory Study, Doctoral dissertation, University of Southampton.

Johnson, R. and Waterfield, J. (2004) 'Making words count: the value of qualitative research', Physiotherapy Research International, Vol. 9, No. 3, pp.121-131.

Jones, J. (2009) 'Selection of grounded theory as an appropriate research methodology for a dissertation: one student's perspective', Grounded Theory Review, Vol. 8, No. 2, pp.23-34.

Jones, R. and Noble, G. (2007) 'Grounded theory and management research: a lack of integrity?', Qualitative Research in Organizations and Management: An International Journal, Vol. 2, No. 2, pp.84-103.

Kolb, S.M. (2012) 'Grounded theory and the constant comparative method : valid research strategies for educators', Journal of Emerging Trends in Educational Research and Policy Studies, Vol. 3, No. 1, pp.83-86.

Kosko, B. (1992) Neural Networks and Fuzzy Systems: A Dynamical Systems Approach to Machine Intelligence, Saga, London.

Krippendorff, K. and Weber, R.P. (1987) 'Basic content analysis', Journal of the American Statistical Association, Vol. 82, No. 397, p.354.

Kumar, M., Vaishya, R. and Parag, P. (2018) 'Real-time monitoring system to lean manufacturing', Procedia Manufacturing, Vol. 20, pp.135-140, doi: 10.1016/j.promfg.2018.02.019.

LeCompte, M. and Goetz, J. (1982) 'Problems of reliability and validity in ethnographic research', Review of Educational Research, Vol. 52, No. 1, pp.31-60.

Leedy, P. (1997) Practical Research: Planning and Design, 6th ed., Merrill, London.

Liamputtong, P. and Ezzy, D. (2009) Qualitative Research Methods, Oxford University Press, Oxford.

Lietz, C. and Zayas, L. (2010) 'Evaluating qualitative research for social work practitioners', Advances in Social Work, Vol. 11, No. 2, pp.188-202.

Lincoln, Y. and Guba, E. (1985) Naturalistic Inquiry, Sage, London.

Locke, K. (2001) Grounded Theory in Management Research, Sage, New York; London.

Marcos-Cuevas, J. (2006) Learning and Knowledge Processes in an Academic-Management Consulting Research Programme: The Case of the MC Centre, Cranfield University.

Mason, J. (1996) Qualitative Researching, Sage, London.

McGhee, G., Marland, G.R. and Atkinson, J. (2007) 'Grounded theory research: literature reviewing and reflexivity', Journal of Advanced Nursing, Vol. 60, No. 3, pp.334-342.

McLaughlin, P., Bessant, J. and Smart, P. (2010) Developing an Organizational Culture that Facilitates Radical Innovation in a mature Small To Medium Sized Company: Emergent Findings, pp.1-29.

Mead, G. (1934) Mind, Self and Society, University of Chicago Press, Chicago.

Merriam, S.B. and Tisdell, E.J. (2015) Qualitative Research: A Guide to Design and Implementation, John Wiley and Sons, London.

Miles, M. and Huberman, A. (1994) Qualitative Data Analysis: An Expanded Sourcebook, Sage, London.

Oates, B.J. (2009) Researching Information Systems and Computing, Sage Publications, London, Thousand Oaks, Calif.

Oxford Dictionary (2014) Gamete: Definition, Oxford dictionary (British \{\&\} World English) Oxford University Press.

Padgett, D. (2008) Qualitative Methods in Social Work Research, Sage Publications, Los Angeles. 
Partington, D. (2002) Essential Skills for Management Research-Grounded Theory, Sage, London.

Patton, M.Q. (2014) Qualitative Research and Evaluation Methods: Integrating Theory and Practice: Integrating Theory and Practice, Sage Publications, London.

Pearse, N. and Kanyangale, M. (2009) 'Researching organizational culture using the grounded theory method', The Electronic Journal of Business Research, Vol. 7, No. 1, pp.67-74.

Phillips, M. (1994) 'Industry mindsets: exploring the cultures of two macro-organizational settings', Organization Science, Vol. 5, No. 3, pp.384-402.

Plummer, M. and Young, L.E. (2010) 'Grounded theory and feminist inquiry: revitalizing links to the past', Western Journal of Nursing Research, Vol. 32, No. 3, pp.305-321.

Punch, K.F. (2005) Introduction to Social Research: Quantitative and Qualitative Approaches, Vol. 2, p.320, UK.

Rashid, H. (2010) Human Factors Effects in Helicopter Maintenance: Proactive Monitoring and Controlling Techniques, Cranfield University.

Ravikumar, M.M., Marimuthu, K., Parthiban, P. and Zubar, H.A. (2016) 'Evaluating lean execution performance in Indian MSMEs using SEM and TOPSIS models', International Journal of Operational Research, Vol. 26, No. 1, p.104.

Robson, C. (2002) Real World Research, 2nd, ed., Blackwell Publishing, London.

Sackmann, S. (1991) 'Uncovering culture in organizations', The Journal of Applied Behavioral Science, Vol. 27, No. 3, pp.295-317.

Sackmann, S.M. (2006) Success Factor: Corporate Culture: Developing a Corporate Culture for High Performance and Long Term Competitiveness: Six Best Practices, Verlag Bertelsmann Stiftung, Gütersloh.

Saunders, M., Lewis, P. and Thornhill, A. (2009) Research Methods for Business Students, Financial Times Prentice Hall, London.

Schein, E. (1985) Organisational Culture and Leadership: A Dynamic View, San Francisco.

Schein, E.H. (1984) 'Coming to a new awareness of organizational culture', Sloan Management Review, Vol. 25, No. 2, pp.3-16.

Schein, E.H. (1990) 'Organizational culture’, American Psychologist, Vol. 45, No. 2, pp.109-119.

Schneider, M., Shnaider, E., Kandel, A. and Chew, G. (1998) 'Automatic construction of FCMs', Fuzzy Sets and Systems, Vol. 93, No. 2, pp.161-172.

Schwandt, T. (1998) Constructivist, Interpretivist Approaches to Human Inquiry, Sage, Thousand Oaks, CA.

Scott, P., Haworth, J., Conrad, C. and Neumann, A. (1993) 'Notes on the classroom as field setting: learning and teaching qualitative research in higher education', Qualitative Research in Higher Education, Vol. 3, No. 6, pp.3-24.

Silverman, D. (2006) Interpreting Qualitative Data: Methods for Analyzing Talk, Text and Interaction, 3rd ed., Sage, Los Angeles.

Srubar, I. (1998) 'Phenomenological analysis and its contemporary significance', Human Studies, Vol. 21, No. 2, pp.121-139.

Stern, P. (1994) 'Eroding grounded theory', in Critical Issues in Qualitative Research Methods, p.212-223, Saga, London.

Stern, P.N. (1980) 'Grounded theory methodology: its uses and processes', Image, Vol. 12, No. 1, pp.20-23.

Strauss, A. (1987) Qualitative Analysis for Social Scientists, Cambridge University Press, London.

Strauss, A. (1993) Continual Permutations of Action, Aldine De Gruyter, New Your.

Strauss, A. and Corbin, J. (1994) 'Grounded theory methodology', in Handbook of Qualitative Research, pp.273-285, Saga, New York.

Strauss, A. and Corbin, J. (1998) Basics of Qualitative Research: Procedures and Techniques for Developing Grounded Theory, Sage, New York. 
Suddaby, R. (2006) 'From the editors: what grounded theory is not', Academy of Management Journal, Vol. 49, No. 4, pp.633-642.

Taylor, G.R. (2005) Integrating Quantitative and Qualitative Methods in Research, University Press of America, New York.

Taylor, S. and Bogdan, R. (1998) Introduction to Qualitative Research Methods: A Guidebook and Resource Saga, London.

Tobin, G.A. and Begley, C.M. (2004) 'Methodological rigour within a qualitative framework', Journal of Advanced Nursing, Vol. 48, No. 4, pp.388-396.

Trochim, W. and Donnelly, J. (2001) Research Methods Knowledge Base, Saga, New York.

Tsang, E.W. and Kwan, K. (1999) 'Replication and theory development in organizational science: a critical realist perspective', Academy of Management Review, Vol. 24, No. 4, pp.759-780.

von Wright, G.H. (2004) Explanation and Understanding, Cornell University Press, Saga, New York.

Walker, D. and Myrick, F. (2006) 'Grounded theory: an exploration of process and procedure', Qualitative Health Research, Vol. 16, No. 4, pp.547-559.

Webb, E., Campbell, D. and Schwartz, R. (1966) Unobtrusive Measures: Nonreactive Research in the Social Sciences, Rand McNally, Chicago.

Weber, R. (2004) 'The rhetoric of positivism versus interpretivism: a personal view', MIS Quarterly, Vol. 28, No. 1, pp. 3-12.

Willis, J., Jost, M. and Nilakanta, R. (2007) Foundations of Qualitative Research: Interpretive and Critical Approaches, Sage Publications, Saga, New York.

Winston, R. and Heiko, L. (1990) 'Just-in-time and small business evolution', Entrepreneurship Theory and Practice, Vol. 14, No. 4, pp.51-64.

Wood, L.C., Wang, W.Y.C. and Duong, L.N.K. (2018) 'A review and reflection on inventory management of perishable products in a single-echelon model', International Journal of Operational Research, Vol. 31, No. 3, p.313.

Woodrum, E. (1984) 'Mainstreaming content analysis in social science: methodological advantages, obstacles, and solutions', Social Science Research, Vol. 13, No. 1, pp.1-19.

Yin, R.K. (2009) Case Study Research: Design and Methods, Thou (ed.) Sage, Thousand Oaks, CA. 


\title{
A methodology to surface aspects of organizational culture to facilitate lean implementation within SMEs
}

\author{
Alkhoraif, Abdullah
}

Inderscience

\author{
Alkhoraif A, McLaughlin P. (2020) A methodology to surface aspects of organizational culture to \\ facilitate lean implementation within SMEs. International Journal of Operational Research, \\ Volume 40, Issue 1, 2021, pp. 52-91 \\ https://doi.org/10.1504/IJOR.2020.10017006 \\ Downloaded from Cranfield Library Services E-Repository
}

